Cómo citar este artículo / How to cite this article: Niveau de Villedary y Mariñas, A. M. (2019). La etapa arcaica de la ciudad fenicia de Gadir. Lucentum, XXXVIII, 111-138. http://dx.doi.org/10.14198/LVCENTVM2019.38.05

\title{
LA ETAPA ARCAICA DE LA CIUDAD FENICIA DE GADIR*
}

\author{
THE ARCHAIC PERIOD OF THE PHOENICIAN CITY OF GADIR
}

\author{
ANA MARÍA NIVEAU DE VILLEDARY Y MARIÑAS \\ Universidad de Cádiz \\ anamaria.niveau@uca.es \\ http://orcid.org/0000-0002-8888-1169
}

Recepción: 17-03-2019

Aceptación: 01-07-2019

\section{Resumen}

El objetivo de este trabajo es intentar reconstruir la topografía y la morfología de la antigua fundación tiria a partir de los datos materiales aportados por las intervenciones arqueológicas más recientes. A los primeros restos aislados y descontextualizados, se han incorporado en los últimos quince años una serie de contextos y secuencias estratigráficas que confirman la ubicación y antigüedad de la ciudad de Gadir de acuerdo a la tradición literaria e historiográfica y hacen posible, si bien de forma preliminar, desentrañar el entramado urbano de la misma y la articulación de los diferentes elementos y sectores reconocidos: áreas residenciales, zonas periurbanas, puertos, necrópolis, espacios de culto, etc.

Palabras clave. Gadir; colonización fenicia; ciudad arcaica; entramado urbano.

\begin{abstract}
This paper tries to reconstruct the topography and morphology of the ancient Tyrian foundation of Gadir through the study of the material data provided by the most recent archaeological works. In the last fifteen years, the first isolated and decontextualized remains have been supplemented by a series of stratigraphic contexts and sequences that confirm the location and antiquity of the city of Gadir according to literary and historiographical tradition. Although on a preliminary basis, this makes possible to unravel its urban plan, as well as the articulation of the different elements and recognized sectors: residential areas, peri-urban areas, ports, necropolis, places of worship, etc.
\end{abstract}

Key words. Gadir; Phoenician colonization; archaic city; urban fabric.

\footnotetext{
* Este trabajo se ha realizado gracias a una estancia de investigación en la Universidad de Oxford entre los meses de febrero y abril de 2017 dentro del Programa «Salvador de Madariaga» del Plan Estatal de Investigación Científica, Técnica e Innovadora (2013-2016) del Ministerio de Educación, Cultura y Deporte, y se inscribe en el marco de actuación del Grupo de Investigación «PHOENIX MEDITERRANEA»: Protohistoria de Andalucía Occidental (HUM-509) del PAIDI y del Campus Internacional de Excelencia del Mar (CEIMar).
} 


\section{INTRODUCCIÓN}

A pesar de tratarse de una de las ciudades más citadas (que no conocidas) de la Antigüedad -en parte debido a su situación geográfica en el extremo occidental del Mediterráneo y a su condición de puente hacia el Atlántico-, lo que sabemos sobre la fundación tiria y el posterior desarrollo de la ciudad de Gadir no se corresponde con la importancia teórica que se le ha otorgado en la historiografía posterior (Ramírez Delgado, 1982). Durante siglos la historia de Gadir se ha escrito a base de especulaciones que han terminando por convertir en verdades lo que no dejan de ser leyendas forjadas e incrementadas a lo largo del tiempo (Niveau de Villedary, 2010; 2019a). A esto ha contribuido, sin duda, que durante siglos la ciudad antigua se mostrara esquiva y los restos arqueológicos, la mayor parte de las veces, hayan aparecido de forma aislada y fortuita. Esta circunstancia ha avivado la leyenda y ha impedido que hasta hace relativamente escasas décadas no se hayan llevado a cabo propuestas maduras y serias (aunque siempre en el terreno de la hipótesis, dada la falta de datos) de reconstrucción de la ciudad antigua (Niveau de Villedary, e.p.). Paradójicamente, una vez aparecidos (y reconocidos como tales) los primeros restos fenicios arcaicos contextualizados, los hallazgos se han ido sucediendo, lo que permite, en el estado actual del conocimiento, que hoy en día podamos lanzar propuestas fundadas en datos objetivos (y no en meras suposiciones) no sólo del lugar donde se levantó la ciudad fundada por los tirios o de su antigüedad real, sino también de su extensión, de su evolución y de las distintas zonas que conformaron el asentamiento. Conocemos mejor, gracias a los descubrimientos del Teatro Cómico (Gener et al., 2012; 2014a; Torres et al., 2014; 2018; Zamora et al., 2010), las áreas residenciales que las públicas, de las que por ahora solo podemos hipotetizar sobre su ubicación y naturaleza, también tenemos más información sobre las zonas de trabajo que surgen alrededor de los puertos - como las ubicadas en la orilla del canal en el Teatro Andalucía (Cobos et al., 1995-96) o la c/ Cánovas del Castillo (Córdoba y Ruiz Mata, 2005)- que de otras áreas industriales o periurbanas, sobre todo de las ubicadas en el entorno de la isla mayor (Muñoz, 1995-96; Lavado et al., 2000; Gener et al., 2014b); apenas si tenemos datos de estos primeros momentos fundacionales de los templos $\mathrm{u}$ otras áreas sacras, y tan solo indicios de las características y localización del cementerio primitivo (Sáez y Belizón, 2014); pero, sin embargo, la suma de todos estos datos permite articular o, al menos, lanzar una propuesta sobre la organización urbana de la primera ciudad de Gadir.

Nuestra intención en este trabajo es plantear una reconstrucción topográfica, morfológica y funcional de las primeras etapas de la ciudad fenicia con la información disponible, sumando los datos descontextualizados y casuales que tuvieron lugar en tiempos pasados a las investigaciones más recientes fruto de trabajos científicos realizados con metodología actualizada; una

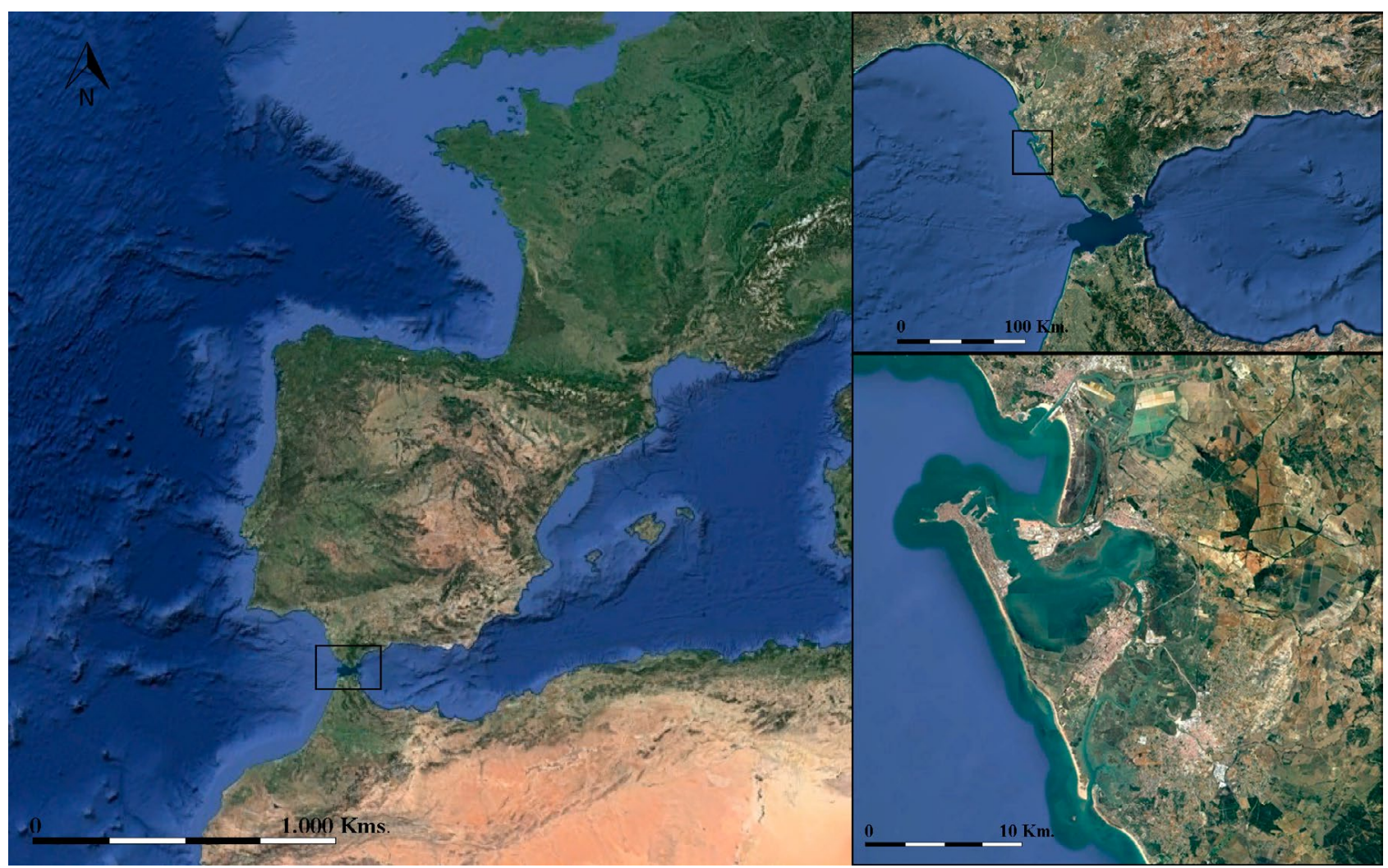

Figura 1: Localización de la ciudad de Cádiz (España). CAutora, a partir de Google Earth. Imagen tomada el 15 de febrero de 2017 
propuesta que, por otra parte, no deja de ser personal, y por ello criticable desde otras posturas y, sobre todo, provisional si, como es de prever, el progreso continuo del conocimiento nos haga avanzar cada vez más rápido en el conocimiento de la ciudad fenicia extremo-occidental.

\section{LA IMAGEN MÍTICA DE GADIR Y EL ANTI- GUO PAISAJE FENICIO}

De acuerdo con la tradición clásica (Veleyo Paterculo, Hist. Rom, I: 2, 1-3; Estrabón, III, 5, 5; Mela, III, 6, 46; Pseudo-Aristóteles, De mirabil. ausc. 134), los tirios fundaron Gadir en el Extremo Occidente del Mediterráneo, bajo la actual ciudad de Cádiz (SW de España) (Fig. 1), unos 80 años después de la caída de Troya (ca. 1104-1003 a. C.). La datación, excesivamente alta, resulta sin embargo representativa de la idea generalizada que se tenía acerca de la edad de la ciudad en la propia Antigüedad Clásica. Según relata Estrabón siguiendo a Posidonio (III, 5, 5), la fundación tuvo lugar tras dos intentos previos a ambos lados de las «Columnas de Herakles» (el Estrecho de Gibraltar) que resultaron fallidos.

Pese a la existencia de estas referencias, la información que los escritores griegos y romanos ofrecen sobre el origen fenicio de la ciudad resulta, en conjunto, escasa y sesgada (Fernández Camacho, 2016), hasta el punto que se ha defendido que la ausencia de noticias sea un acto consciente, como parte de una estrategia de mitificación por parte de los griegos que convierten todos los confines del mundo conocido en territorios ignotos, poblados por seres mitológicos y bárbaros. Un escenario propicio para situar algunas de las hazañas de Herakles, el héroe colonizador por antonomasia (Fernández Camacho, 2015).

Otra de las principales dificultades a la hora de identificar los antiguos topónimos y la ubicación de los núcleos de asentamiento y de los templos citados por las fuentes escritas es la gran transformación que ha sufrido el paisaje en los últimos tres mil años (Aubet, 2009: 271 ss.) (Fig. 2), circunstancia en parte enmendada gracias a la realización de estudios geoarqueológicos, que han posibilitado la reconstrucción del paisaje fenicio. Cabe citar los trabajos pioneros de Juan Gavala y Laborde (1992 [1959]) y los más recientes del equipo liderado por Oswaldo Arteaga, por la parte española, y Horst D. Schulz, por la alemana, enmarcados en un proyecto más amplio encaminado a reconstruir la paleocosta andaluza mediterránea (Arteaga et al., 1987), incluidas las marismas del Guadalquivir (Arteaga y Roos, 1995; Arteaga et al., 1995) y la bahía de Cádiz (Arteaga y Roos, 2002; Arteaga et al. 2008). En este sentido, aunque con hipótesis y resultados diferentes en algunos aspectos, sobre todo en relación a la naturaleza, al trazado y al momento en el que se colmata el canal interior, viene trabajando desde hace años un equipo de la Universidad de Cádiz (Llave et al., 1999).

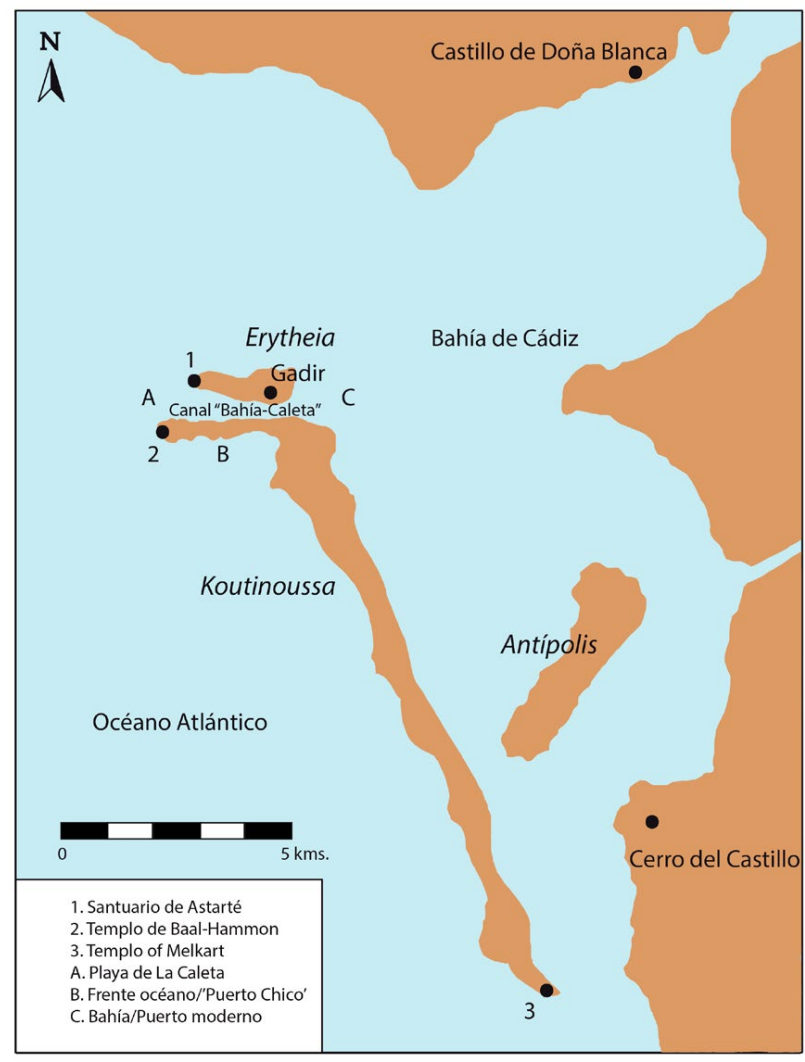

Figura 2: Reconstrucción paleotopográfica de la Bahía de Cádiz en época fenicia en la actualidad, con identificación de las islas citadas por las fuentes escritas (Erytheia, Koutinoussa y Antipolis), los templos (Afrodita/Venus Marina/Astarte, BaalHammon/Kronion, Melqart/Herakleion), el núcleo urbano insular (Gadir) y los asentamientos continentales (Castillo de Doña Blanca, El Puerto de Santa María y Cerro del Castillo, Chiclana de la Frontera). (CAutora

La actual ciudad de Cádiz, hoy situada en una península alargada que se une al continente por una estrecha lengua de tierra de $14 \mathrm{~km}$ de longitud, en aquellos momentos formaba parte de un archipiélago constituido al menos por tres islas que se han identificado con las citadas por los autores clásicos. Al norte se emplaza la isla menor, delimitada por una lengua de mar cegada desde época romana debido a causas antrópicas, conocida por «canal Bahía-Caleta» (Niveau de Villedary, 2010: 637) (Fig. 3). La mayor parte de los autores clásicos y actuales sitúan en ella la ciudad antigua fenicia (Plinio, H.N., IV, 36, 120) y el santuario de Venus Marina, la fenicia Astarté (Avieno, O.M., 319317). Al otro lado del antiguo curso de agua se localiza la isla mayor, de forma alargada, llamada Kotinoussa por Timeo (Plinio, H.N., IV, 4, 119-120). En esta isla se levantaron los templos dedicados a Kronos (en origen Baal-Hammón), en el extremo norte y a Herakles (el fenicio Melqart), en el sur. También pudo ser el lugar al que se trasladó la ciudad púnica una vez abandonado el núcleo original al norte del canal, expandiéndose en época romana ante la falta de espacio (Estrabón, III, 5, 3). Una tercera isla se correspondería con la moderna «Isla de León», donde se asienta la actual población 


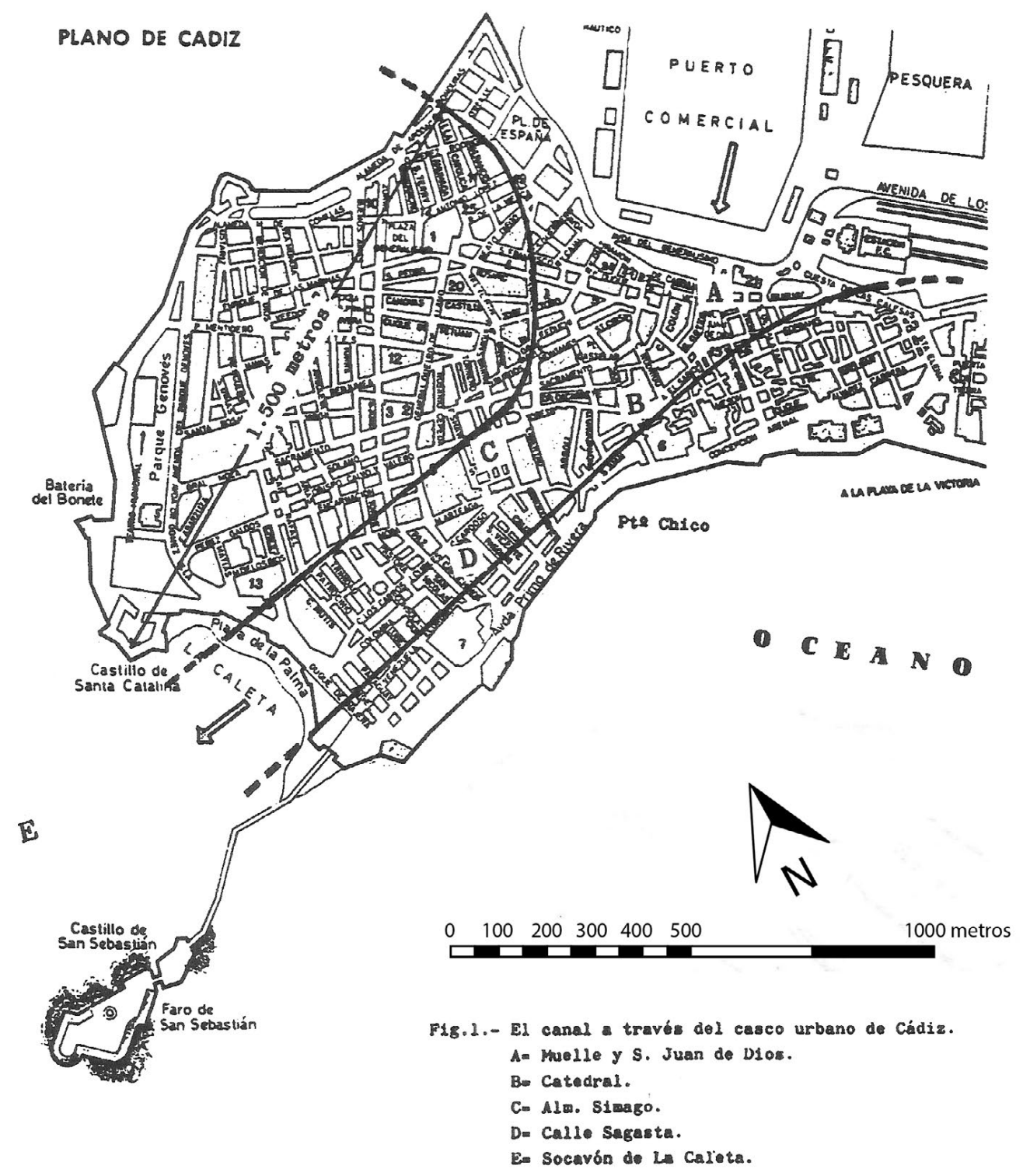

Figura 3: Propuesta de trazado del antiguo canal «Bahía-Caleta» que atravesaría el casco histórico de la ciudad de Cádiz (según Ponce, 2000: 912, fig. 1)

de San Fernando. Generalmente se identifica con la Antípolis de las fuentes, aunque no existe unanimidad sobre ello entre los diferentes autores: ni clásicos, ni modernos, seguramente porque pronto perdió su carácter insular.

Este paisaje no puede entenderse sin el hinterland continental (Botto, 2014) (Fig. 4). Desde un momento temprano se levantan dos grandes asentamientos en tierra firme. El Castillo de Doña Blanca (El Puerto de Santa María, Cádiz), junto a la desembocadura del Guadalete, puede considerarse el gran establecimiento fenicio continental, siguiendo el modelo dual isla-costa de la ciudad de Tiro (Ruiz Mata, 2016: 314). Se trata de un asentamiento de características urbanas, amurallado y con una arquitectura oriental desde su mismo origen a comienzos del s. VIII a. C. (Ruiz Mata, 1999: 303-306). En el sur se sitúa el yacimiento del Cerro del Castillo, emplazado en la zona alta del casco urbano de la actual población de Chiclana de la Frontera (Bueno, 2014). El asentamiento, amurallado desde al menos el s. VII a. C., se sitúa en tierra firme, junto a la antigua desembocadura del río Iro y frente a la ubicación tradicional del templo de Melqart. Una posición estratégica que permite controlar de manera tanto efectiva como simbólica el límite meridional del territorio de Gadir.

La integración de todos estos datos en un modelo de explicación global se concreta en la tesis propuesta por Diego Ruiz Mata a fines del milenio (1999), que considera que bajo el término Gadir se engloba un concepto integral que incluye todos estos territorios, insulares y continentales, en torno a la bahía de Cádiz. Se plantea la existencia de un patrón de asentamiento polinuclear y funcionalmente disociado (con diferentes núcleos urbanos, centros religiosos, instalaciones industriales, necrópolis, etc.) que encuentra refrendo en la forma plural por la que los griegos nombran a la ciudad: 


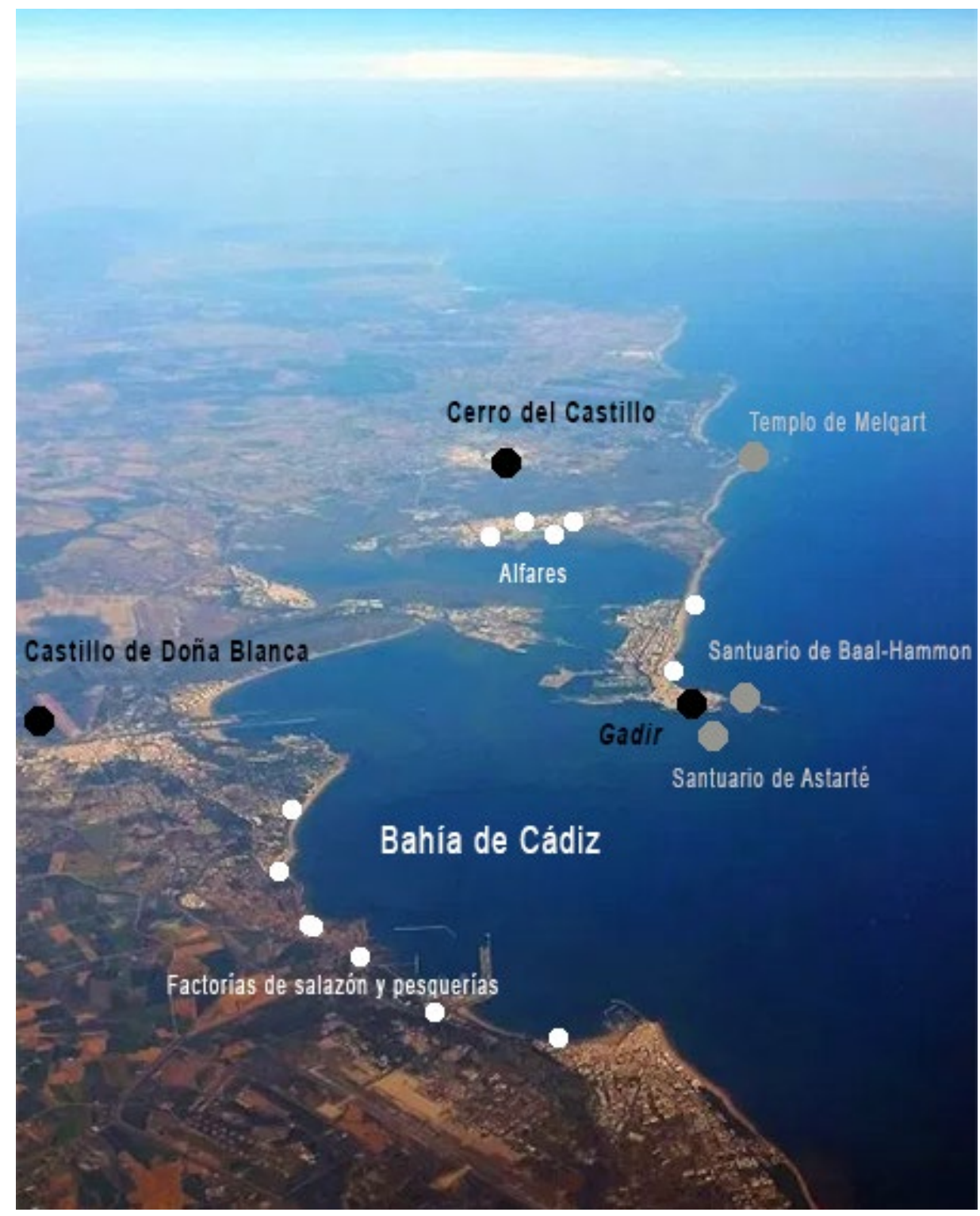

Figura 4: Localización de los asentamientos, santuarios e instalaciones productivas prerromanas en el entorno de la bahía de Cádiz. (C)Autora, a partir de Google Earth. Imagen tomada el 23 de enero de 2019

Gadeira. Esta propuesta es en la actualidad aceptada por la gran mayoría de los investigadores (Sagona, 2004: 254; Prados, 2007: 128-129; Delgado, 2008a: 406; Niveau de Villedary, 2008; 2018; e.p.; Bondì et al., 2009: 236; Domínguez Monedero, 2012; Botto, 2014; Padilla, 2014; Ruiz Mata, 2016; 2018; Escacena 2018, por citar solo los más representativos) y abre una nueva etapa en la historia de la investigación.

\section{LA APARICIÓN DE LA CIUDAD FENICIA (FIG. 5)}

A pesar del cambio de paradigma, a finales del milenio las evidencias materiales de la presencia fenicia en territorio insular eran aún muy escasas y no existían restos arquitectónicos o urbanos claros. En esos momentos los contextos seguros más antiguos eran de naturaleza funeraria, sin que pudieran fecharse con anterioridad a finales del s. VII-s. VI a. C. (Torres, 2010).

\subsection{LOS PRIMEROS HALLAZGOS ARQUEOLÓGICOS}

Los primeros datos son vagos y proceden sobre todo del entorno de Kotinoussa, la isla mayor situada al sur del canal. Son materiales localizados en posición secundaria, como los aparecidos en el vertedero de la c/ Paraguay (CP) (Fig. 5, 1) o en contextos no bien definidos, caso de los restos de estructuras (muros y pavimentos) de Concepción Arenal-c/ Botica (CAr/CB) (Fig. 5, 2), muy afectados por las construcciones posteriores y nunca bien estudiados ni publicados. En un primer momento estos elementos se fecharon considerablemente al alza (Frutos y Muñoz, 2004: 87-88), aunque por la tipología de la cerámica (ánforas fenicias occidentales T-10.1.2.1., 


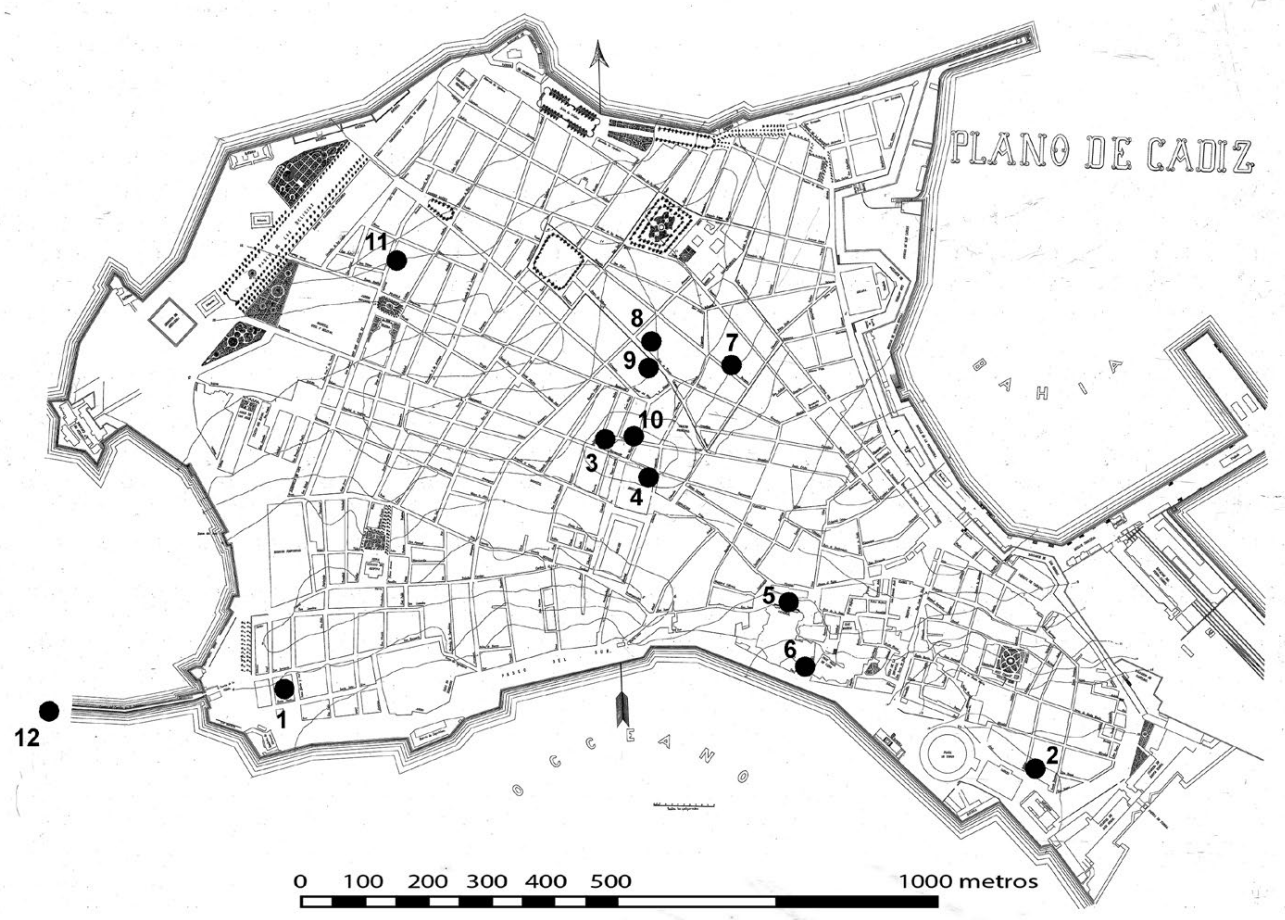

Figura 5: Plano de Cádiz con la localización de los sitios e intervenciones citados en el texto. 1. c/ Paraguay (CP). 2. Concepción Arenal/ Botica (CAr/CB). 3. Torre Tavira/Marqués del Real Tesoro (TT/MRT). 4. Teatro Andalucía (TA). 5. Plaza de la Catedral (PC). 6. Casa del Obispo (CdO). 7. Cánovas del Castillo (CdC). 8. Central Telefónica (CT). 9. c/ Ancha (CA). 10. Teatro Cómico (TC). 11. c/ Hércules $(\mathrm{CH})$. 12. Castillo de San Sebastián (CSS). CAutora

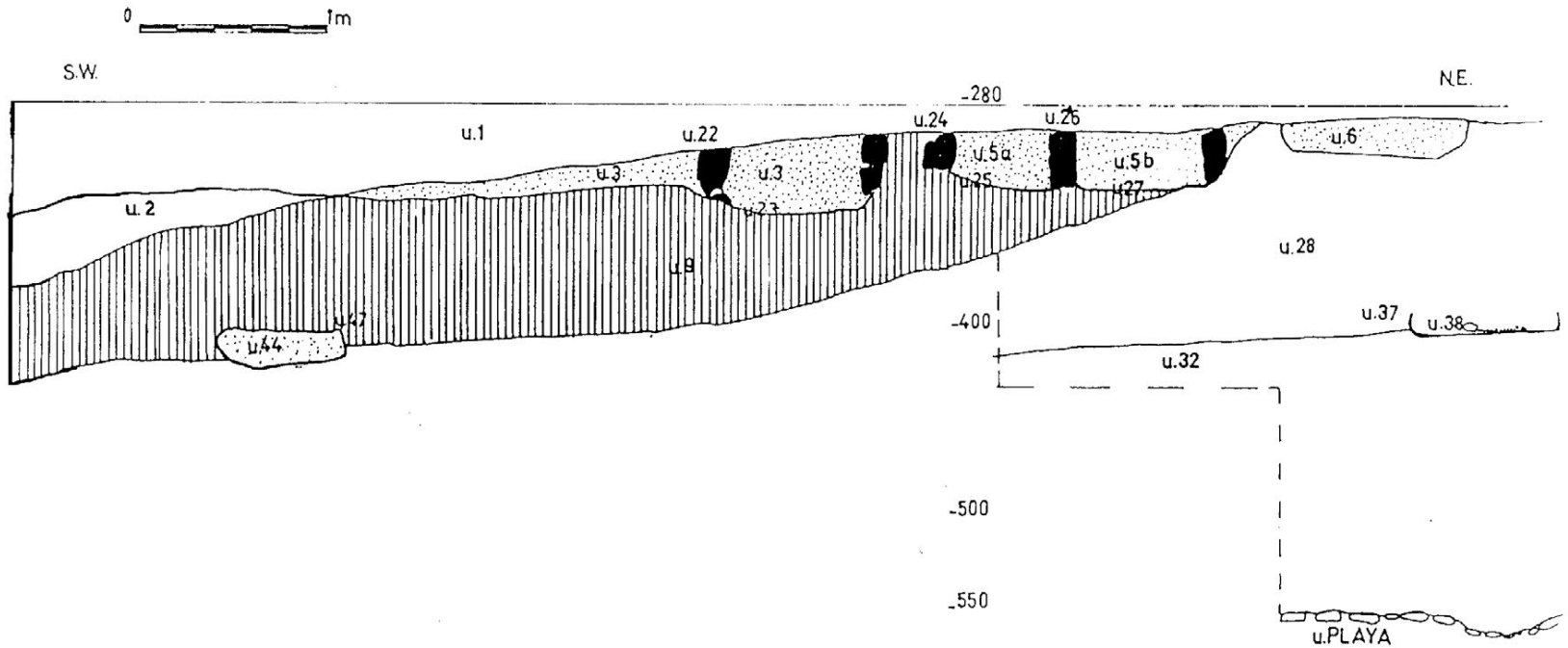

Figura 6: Nivel de playa fenicia y progresiva colmatación del canal «Bahía-Caleta» documentado en el Teatro Andalucía (Cobos et al., 1995-96: 125; fig. 3)

platos de engobe rojo de bordes anchos, lucernas de dos mechas y vasos bícromos) la datación de ambos conjuntos debe rebajarse hasta un momento avanzado del s. VII-s. VI a. C. (o incluso posterior, vid. Ruiz Mata, 2016: 309); aunque perviven algunos elementos residuales que se pueden retrotraer hasta mediados del s. VIII a. C., como un ánfora fenicia oriental del tipo Sagona 2 (Muñoz, 1995-96: 80, fig. 4, 7).

En las mismas fechas se lleva a cabo un sondeo en la c/ Marqués del Real Tesoro, junto a la Torre Tavira, el lugar donde se situaba tradicionalmente el asentamiento fenicio (TT/MRT), en la parte más alta de la isla septentrional (Fig. 5, 3). Los resultados, no obstante, son confusos, pues no queda claro si aparecen o no materiales arcaicos y si se agota o no la potencia estratigráfica (Ruiz Mata, 2016: 308). En otra intervención en la orilla norte del antiguo canal, en el solar del antiguo Teatro Andalucía (TA), también situado en lo que sería Erytheia, (Fig. 5, 4), se documenta la línea de playa arcaica y restos de actividades antrópicas indefinidas 


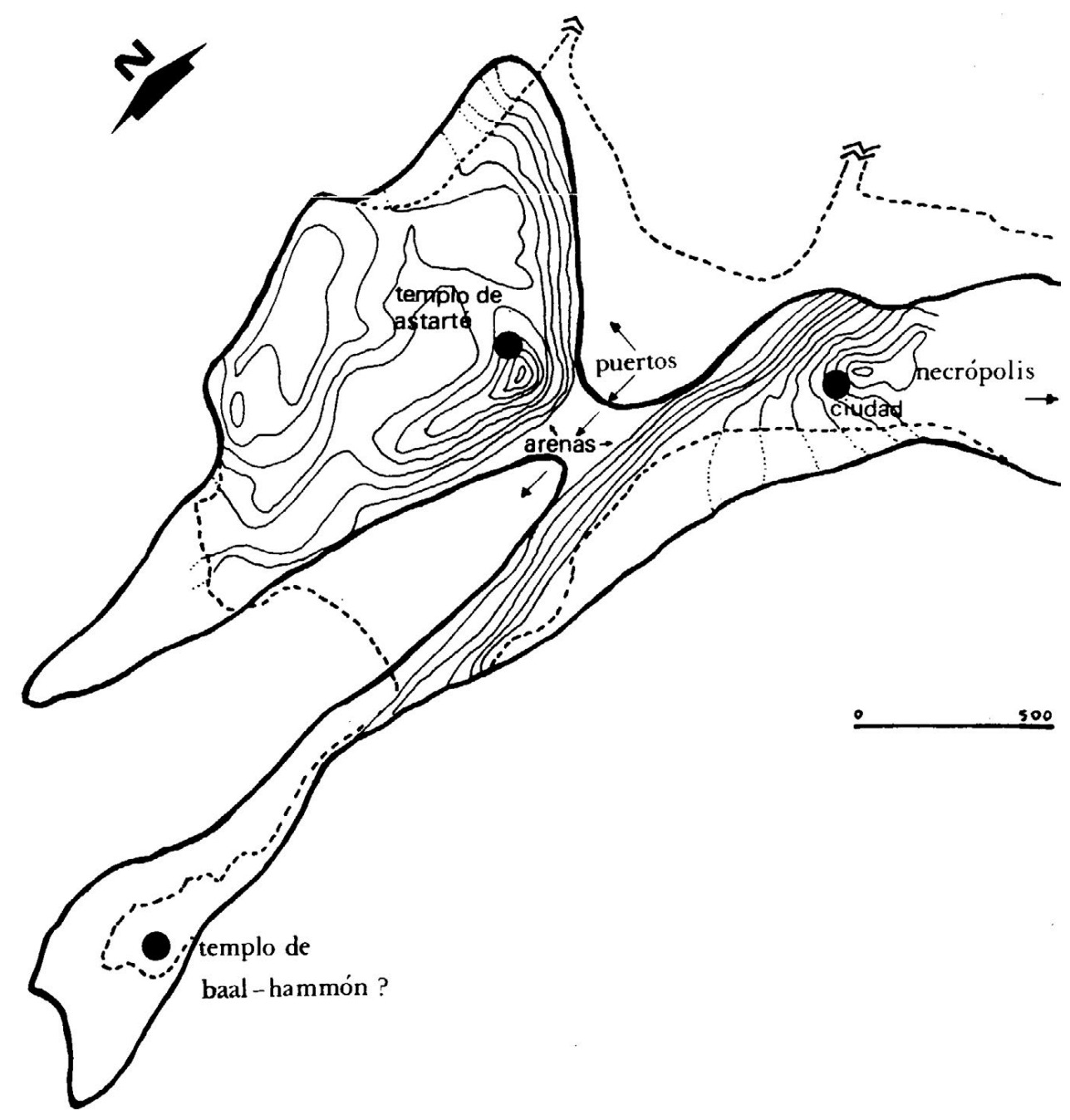

Figura 7: Propuesta de reconstrucción paleotopográfica del asentamiento insular arcaico según Álvarez Rojas, con indicación de la situación de los distintos elementos: ciudad, necrópolis, templos y puertos, una vez cegado el canal en su zona media (Álvarez Rojas, 1992: 29)

que sus excavadores interpretan como «áreas de consumo», con materiales fechados a partir del s. VII a. C. (Fig. 6).

Por último, con el objetivo de delimitar el curso del canal, tienen lugar una serie de sondeos geoarqueológicos que evidencian, por una parte, la existencia de un puerto interior o kothon bajo la actual Plaza de la Catedral (PC), que estaría en funcionamiento ya en época arcaica según los responsables del estudio (Fig. 5, 5); y, por otra, el posible cegamiento del canal desde momentos fenicios (Arteaga y Roos, 2002), como había apuntado años antes Álvarez Rojas (1992: 20) (Fig. 7), afirmación con la que no está de acuerdo un sector de la investigación que sigue defendiendo la navegabilidad del mismo en estas fechas (Abad y Corzo, 2017: 91; Pajuelo, 2017; Niveau de Villedary, e.p.).

\subsection{CONTEXTOS Y SECUENCIAS ESTRATIGRÁFICAS FENI- CIAS}

No es sino a finales del milenio cuando aparecen y se excavan por primera vez estratigrafías y contextos fenicios inequívocos. De nuevo, las primeras evidencias proceden de la isla de Kotinoussa. Entre 1997 y 2000 se interviene en el palacio episcopal (conocido popularmente por «Casa del Obispo», CdO) (Fig. 5, 6) situado junto a la Catedral actual de la ciudad (Gener et al., 2014b). La excavación ofrece una secuencia ininterrumpida de ocupación del sitio desde el Bronce Final hasta la actualidad. Los niveles inferiores son interpretados por sus excavadores como un área de hábitat «extraurbana», de carácter doméstico. En este primer periodo (Periodo Fenicio A) (Gener et al., 2014b: 123, tabla 1) se distinguen dos fases. De la Fase I procede un edificio de planta rectangular dividido en cuatro estancias, con muros de tapial y pavimentos de arcilla apisonada (Fig. 8). Culturalmente se adscribe a un momento indeterminado del Bronce Final, aunque ya en contacto con las poblaciones orientales y se fecha hacia el 820-800 a. C. (Gener et al., 2014b: 123). A fines del s. VIII a. C. estas construcciones son destruidas por un incendio y la zona no se vuelve a ocupar hasta el s. VII (Fase II), estando en uso hasta el s. VI avanzado, según el material recuperado (Gener et al., 2014b: 127, fig. 2, d). En esta segunda fase fenicia la 


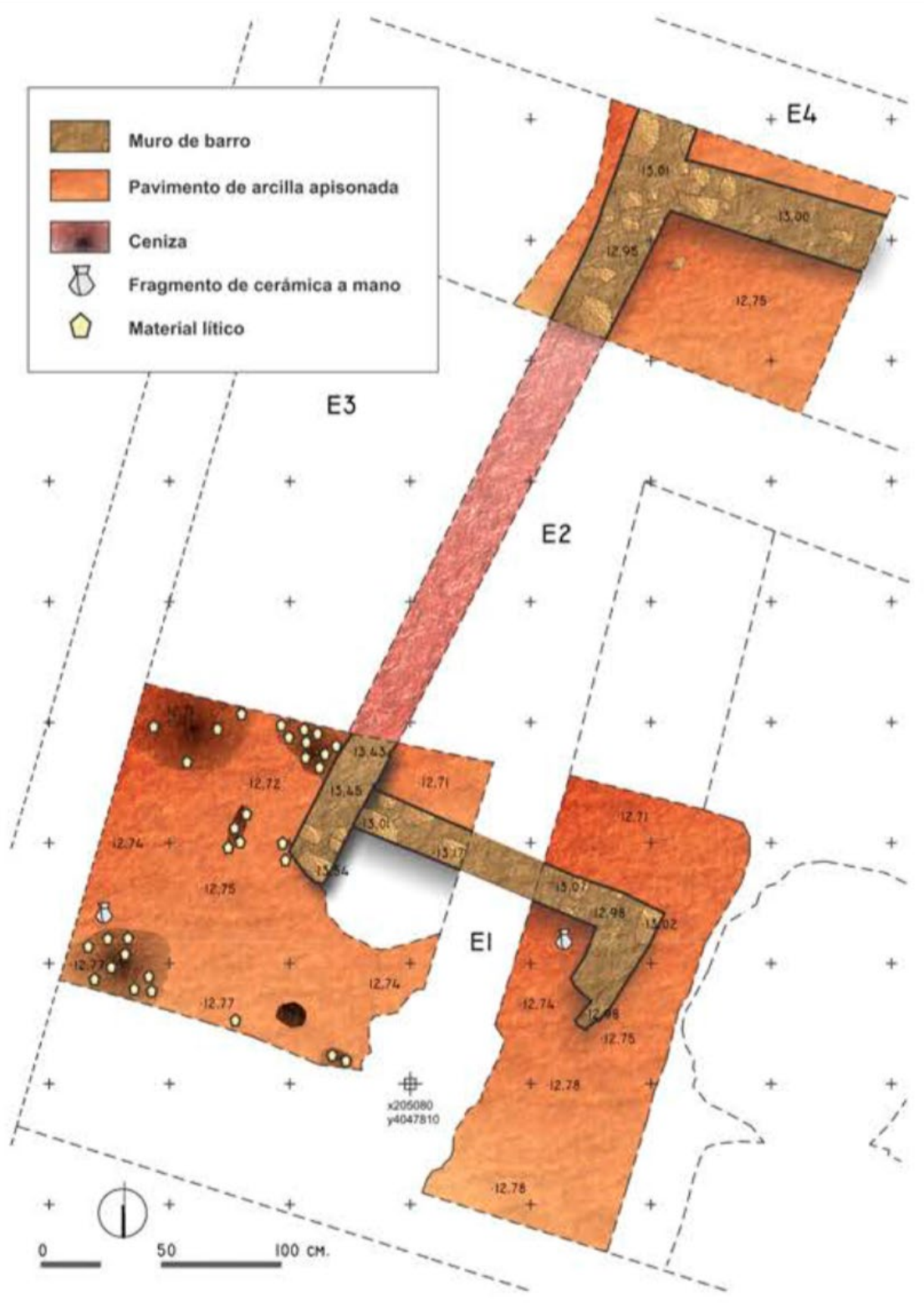

Figura 8: Planta de la Fase I de la Casa del Obispo (Gener et al., 2014b: 126, fig. 2a)

utilización del tapial se alterna con la construcción de muros de adobe, aunque los restos se encuentran muy dañados por las edificaciones posteriores.

De Erytheia, el lugar donde la tradición sitúa la ciudad fenicia original, es de donde proceden las novedades más significativas en relación al asentamiento fenicio arcaico. En 2002 se excava en la c/ Cánovas del Castillo (CdC), en la orilla norte del canal (Fig. 5, 7), un establecimiento temporal sin estructuras permanentes que presenta un único momento de ocupación en torno al s. VIII a. C. (Córdoba y Ruiz Mata, 2005) (Fig. 9, 1 y 3). La presencia relevante de restos ícticos (Fig. 9, 4) junto a materiales cerámicos arcaicos de variada procedencia (fenicia oriental y occidental, indígena y sarda) (Fig. 9, 2) lleva a sus editores a interpretar el sitio como un lugar de trabajo a cielo abierto, que relacionan con la pesca estacional de túnidos (Córdoba y Ruiz Mata, 2005: 1316-1317).
Ese mismo año se excava un nuevo solar en la c/ Ancha, frente a la Central Telefónica (CT) (Fig. 5, 8), el lugar donde en 1928 había aparecido una figura con máscara de oro que hoy se conserva en el Museo Arqueológico Nacional (Madrid). Dicha figurilla, identificada con el dios Ptah (Fig. 10), se halló en el interior de una estructura de sillares de la que sólo se tienen noticias indirectas (Muñoz, 1998: 136-137) y que ha sido interpretada como una tumba monumental (Ruiz Mata et al., 2014: 85 y 108) o un depósito votivo (Ramírez Delgado, 1982: 102). Los nuevos trabajos llevados a cabo en el n. ${ }^{\circ} 29$ de la c/ Ancha (Fig. 5, 9) sacan a la luz un nivel de ocupación fenicio arcaico sin restos constructivos, salvo una fosa en cuyo interior se excava un pozo (Ruiz Mata et al., 2014) (Fig. 11). Ambas estructuras, fosa y pozo, aparecen rellenas de materiales cerámicos y restos óseos. Cronológica y culturalmente consiste en un conjunto similar al excavado 

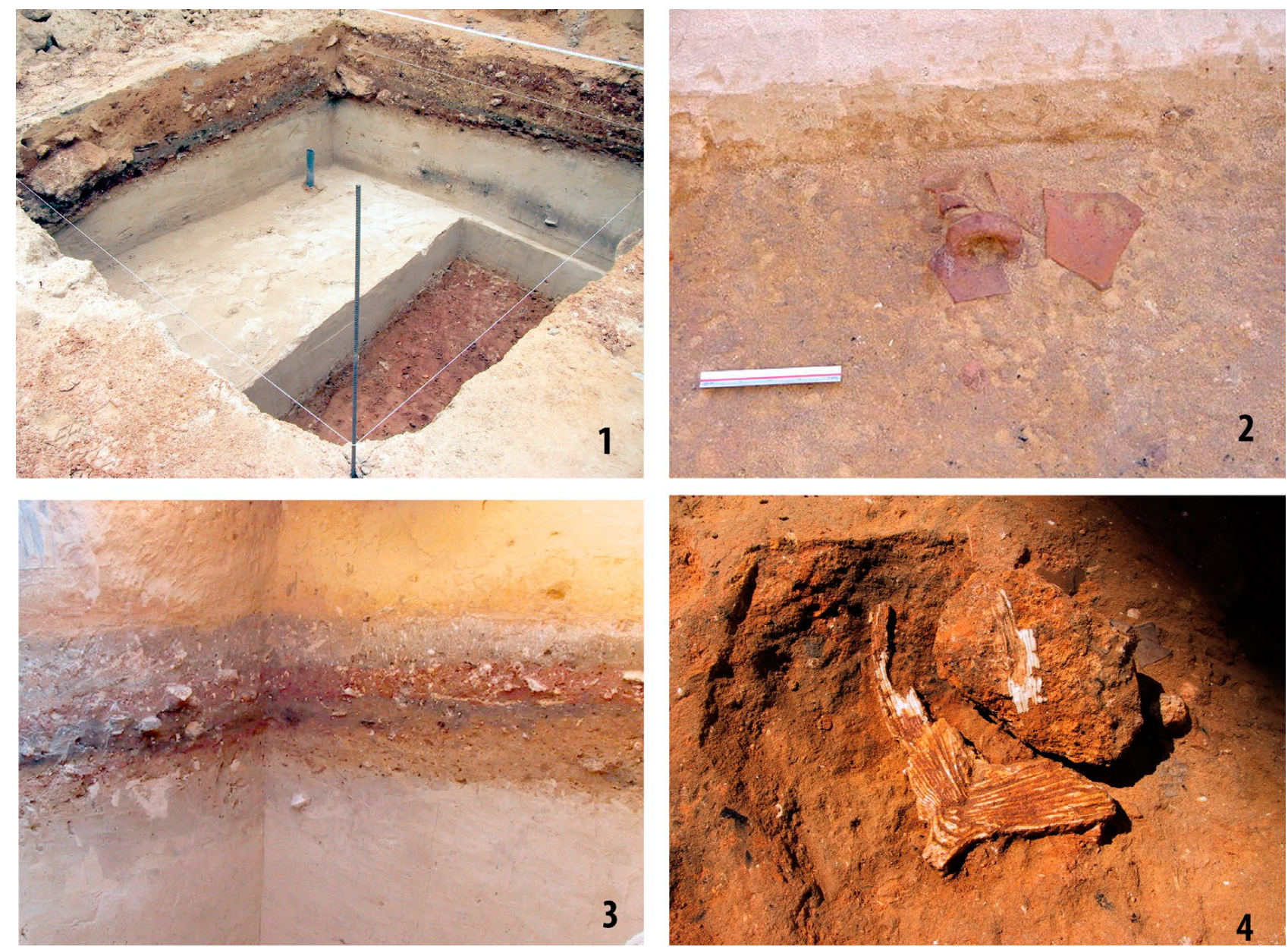

Figura 9: c/ Cánovas del Castillo n. ${ }^{\circ}$ 38. 1. Vista general de la intervención. 2. Detalle de ánforas fenicias in situ. 3. Estratigrafía de la intervención con detalle de los diferentes suelos de ocupación entre estratos estériles de arena dunar de aportación eólica. 4 . Restos de túnidos. Fotografías: Ignacio Córdoba Alonso

en Cánovas del Castillo. En esta zona también se reconoce un único nivel de ocupación que seguidamente se abandona y el lugar no se vuelve a habitar, tras un largo hiatus, hasta el s. III a. C. La interpretación de sus editores es que se trata de un espacio a cielo abierto donde tienen lugar actividades de naturaleza ritual (banquetes, ofrendas, sacrificios), relacionados con la posible necrópolis arcaica que ubican en las proximidades (Ruiz Mata et al., 2014: 114).

No obstante, la intervención llevada a cabo en una zona próxima al lugar más elevado de la isla menor (bajo el antiguo «Teatro Cómico», TC) es la que ha aportado evidencias explícitas del entramado urbano de la antigua ciudad fenicia (Gener et al., 2014a) (Fig. $5,10)$. La excavación ha hecho posible también la documentación de la primera secuencia de habitación fenicia continuada en Erytheia (desde finales del IX a. C. hasta el tercer cuarto del s. VI a. C. aprox.), en la que se distinguen hasta cuatro fases de ocupación de época fenicia (Fig. 12, 1).

- Periodo I (Bronce Final/Fenicio - s. IX ante circa 820/800 a. C., Cota: 5,50 m s.n.m.) (Gener et al., 2014a: 17). Se trata una fase mal conocida que se documenta bajo los restos arquitectónicos del periodo posterior. En ella existen evidencias de la realización de actividades productivas (extracción de púrpura) y se recuperaron fragmentos informes de cerámica a torno que permiten defender un temprano impacto colonial fenicio en la bahía de Cádiz, sin más precisiones (Gener et al., 2014a: 18).

- El Periodo II (Fenicio A - 820/800 y 760/750 a. C., Cota: 6,80/5,50 m s.n.m.) es el mejor conservado, por lo que se priorizó su excavación en extensión (y posterior puesta en valor) (Gener et al., 2014a: 18) (Fig. $12,2)$. Se diferencian hasta tres subfases constructivas (Fase 1: ca. 820-800 a. C., Fase 2: 800-780 a. C. y Fase 3: 780-760/750 a. C.). Presenta un urbanismo planificado y aterrazado en el que se distinguen tres «grupos estructurales» o manzanas, ocho «unidades domésticas» o viviendas y dos «zonas de tránsito» o calles (Gener et al., 2014a: 18-19, figs. 4-5) (Fig. $12,3)$. Se utiliza la arquitectura en tierra, con muros construidos mediante la técnica del tapial y medidas estándar («codo real egipcio»), suelos de arcilla apisonada sobre preparados de cantos y cenizas y posibles cubiertas planas de madera y fibras vegetales. La mayor parte de las viviendas cuentan con equipamientos de carácter doméstico (hornos de tipo tannur, hornillas y 


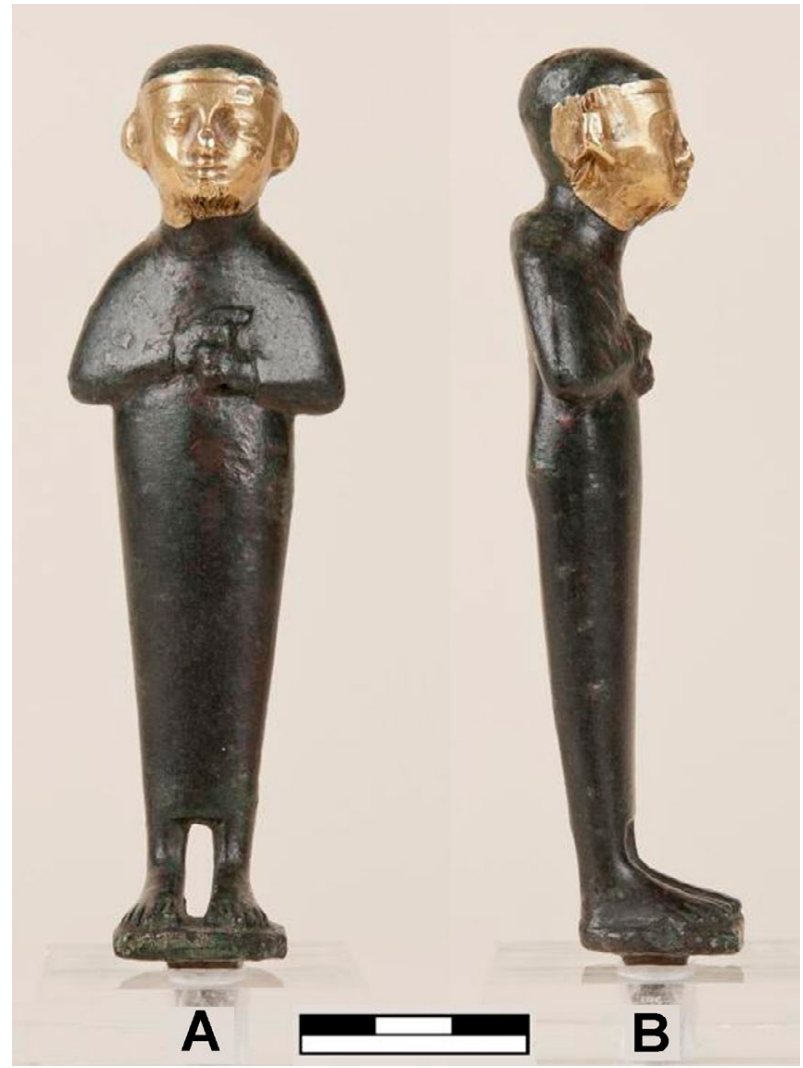

Figura 10: Figurilla de bronce con máscara de oro del dios Ptah hallado en 1928 en la Central Telefónica (c/ Ancha n. ${ }^{\circ}$ 28, Cádiz). Fotografía: Arantxa Boyero Lirón, MAN (N. ${ }^{\circ}$ Inventario: 31920$)$

fogones, banquetas corridas, molinos de mano, zonas de almacenamiento); aunque en estos espacios también tuvieron lugar actividades artesanales (producción alfarera, manufactura de textiles e indicios de producción siderúrgica y metalúrgica). Tradicionalmente se ha considerado que las actividades productivas realizadas en el interior de las casas son llevadas a cabo por mujeres y que se corresponden exclusivamente con una producción destinada al autoconsumo de la unidad familiar (sin entrar, por razones obvias de espacio, si en este caso estamos ante familias nucleares o extensas o si los sirvientes - por ejemplo- estarían integrados en estas unidades familiares). No obstante, este paradigma está siendo cuestionado en los últimos años desde las arqueologías feministas y de género (Delgado, 2016). Tampoco es real -aunque se haya seguido utilizando por pragmatismo- la tradicional distinción entre «espacios públicos» y «espacios privados», heredados de la arqueología tradicional (Delgado, 2016). Desde esta óptica no sabemos hasta qué punto estas producciones artesanales estuvieron destinadas a una esfera doméstica o a obtener excedentes con vistas a su intercambio y comercialización (Delgado, 2016: 70), aunque si esto fue así hubo de ser a un nivel muy elemental, lejos de las actividades productivas a mayor escala inferidas de ciertos lugares como el Cerro del Villar (Delgado, 2008b: 71), lo propios «templos» arcaicos -concebidos como lugares de mercado (López Castro, 2018:
80-82) - o de toda una serie de edificios de mayores dimensiones y funcionalidad eminentemente comercial que se multiplican a partir de la siguiente centuria (Prados 2004). Por otro lado, las dimensiones y características tanto de la arquitectura como del equipamiento y objetos hallados en las viviendas de Teatro Cómico hacen pensar en que se trate de un área residencial de cierta posición social y económica (López Castro, 2017: 201).

- En el Periodo transicional II/III se abandonaron las estructuras anteriores de forma repentina y precipitada a causa de una posible catástrofe natural, de hecho bajo sus muros ha aparecido, al menos, un cadáver in situ. Posteriormente el terreno se allana para la construcción de nuevas edificaciones, ahora de mampostería, dando lugar al Periodo III (Fenicio B - fines s. VIII a. C. y 600/580 a. C. Cota: 7,78 m s.n.m.) (Gener et al., 2014a: 37-38). De este momento sólo se conserva un edificio de cinco estancias y algunos restos de pavimentos, destruidos también por sucesivos «acontecimientos traumáticos» (¿un incendio?), como prueban los dos individuos fallecidos in situ (Gener et al., 2014a: 39-41, n. 169).

- La zona se vuelve a reurbanizar aún una vez más. Las estructuras correspondientes al Periodo IV (Fenicio $\mathrm{C}-2^{\mathrm{o}}$ y $3^{\text {er }}$ cuarto del s. VI a. C. Cota: $8,09 \mathrm{~m}$ s.n.m.) no se conocen bien, ya que han quedado muy destruidas por las construcciones subterráneas posteriores (piletas y cisternas de una factoría de salazones romana). En esta última fase se constata un cambio en la orientación del trazado urbanístico y el antiguo eje SO-NE es sustituido por otro con una orientación exacta N-S (Gener et al., 2014a: 41).

En suma, todos los datos recabados (el urbanismo, la arquitectura doméstica, el empleo de materiales y técnicas constructivas levantinas, el uso de la escritura, las evidencias de prácticas administrativas, la procedencia de la cultura material, etc.) indican el origen oriental de los restos y sitúan el momento de la fundación, según sus excavadores, hacia finales del s. IX a. C. (Torres et al., 2014: 79; 2018: 183), confirmando la ubicación insular del primer asentamiento tirio y la relativa antigüedad del mismo.

En la c/ Hércules $12(\mathrm{CH})$ (Fig. 5, 11), también en Erytheia, se han hallado restos de las que por ahora parecen ser las evidencias funerarias más antiguas de Gadir (Sáez y Belizón, 2014), que se corresponderían con la necrópolis del sector de ciudad exhumado (Fig. 13). Por su parte, las actuaciones llevadas a cabo en el Castillo de San Sebastián (CSS) y bajo las aguas de la playa de La Caleta (LC) en estos últimos años han proporcionado nuevos datos sobre los posibles templos de época fenicia, con restos constructivos constatados al menos desde el s. VII a. C. (Maya et al., 2014) (Fig. 14) y materiales de posible carácter votivo desde la centuria anterior (Saéz e Higueras-Milena, 2016; Higueras-Milena y Sáez, 2018) (Fig. 15). Finalmente, la mayor novedad procede de una excavación llevada a cabo estos últimos años en el solar del Colegio Mayor 

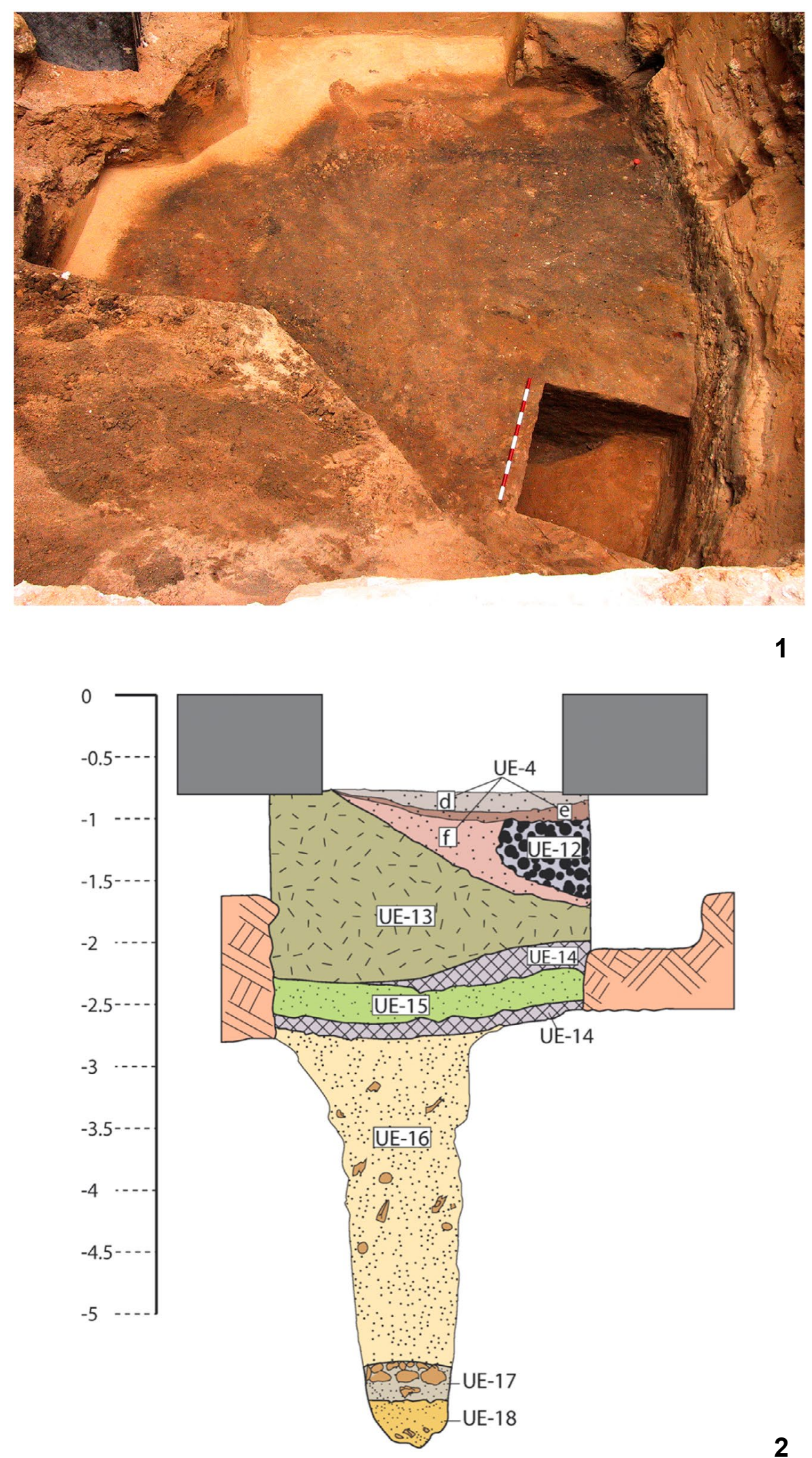

Figura 11: c/ Ancha n. ${ }^{\circ}$ 29. 1. Vista general de la fosa con materiales fenicios y sondeo. Fotografía: Arqueogades S.L. 2. Sección del pozo excavado en la fosa (Ruiz Mata et al., 2014: 91, fig. 5b) 

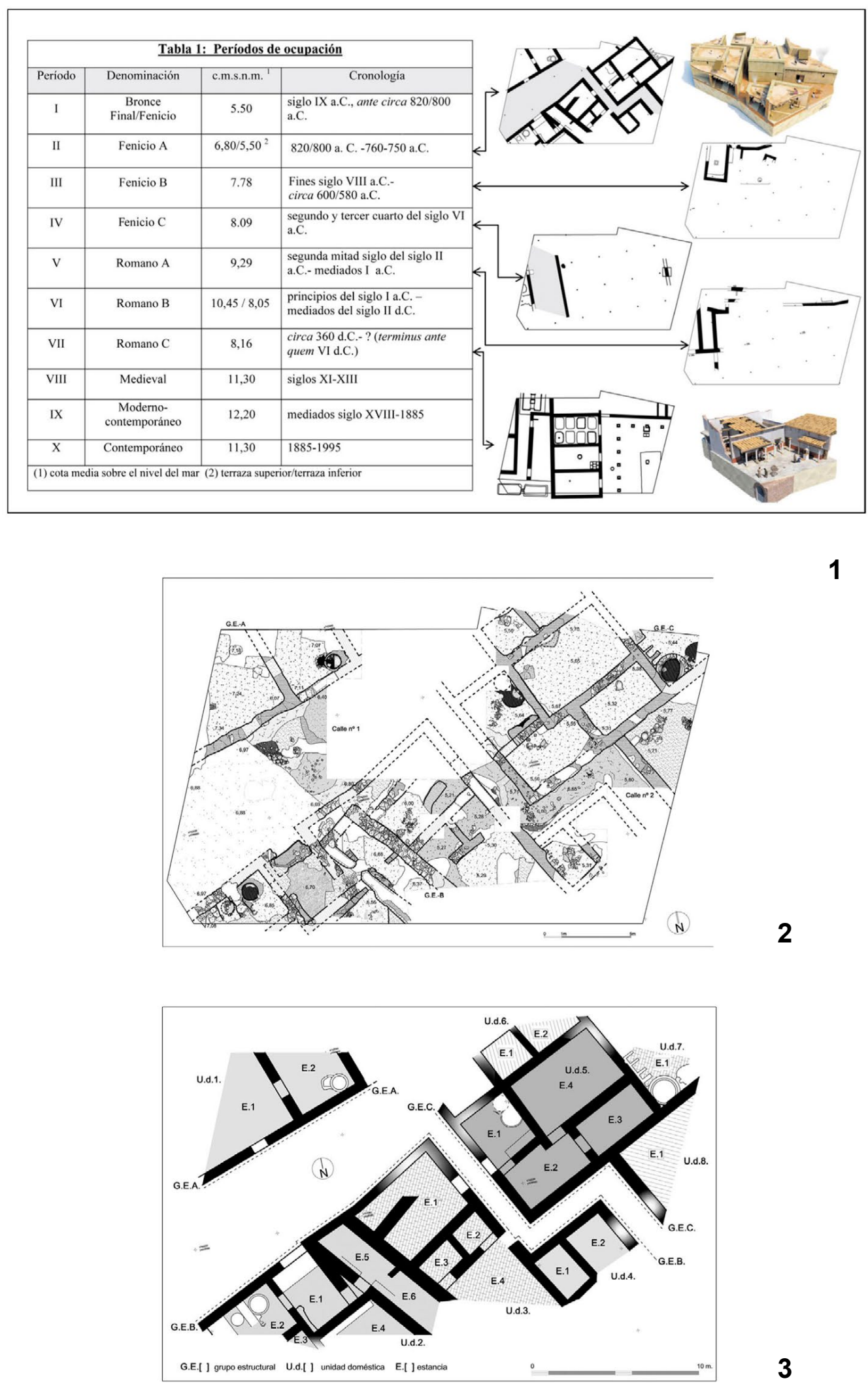

Figura 12: Teatro Cómico. 1. Periodos de ocupación (Gener et al., 2014a: 16, tab. 1). 2. Planimetría del Periodo II, Fenicio A (Gener et al., 2014a: 19, fig. 4). 3. Grupos estructurales y unidades domésticas del Periodo II, Fenicio A (Gener et al., 2014a: 20, fig. 5)

Universitario (CMU) en un terreno no muy lejano a la playa de La Caleta, situado en la zona norte de Erytheia, cercana también a la supuesta necrópolis, donde se ha excavado un pozo en cuyo interior se han hallado materiales fenicios y que sus excavadores comparan con el hallado en c/ Ancha 29 (Sáez et al., 2019). 
1

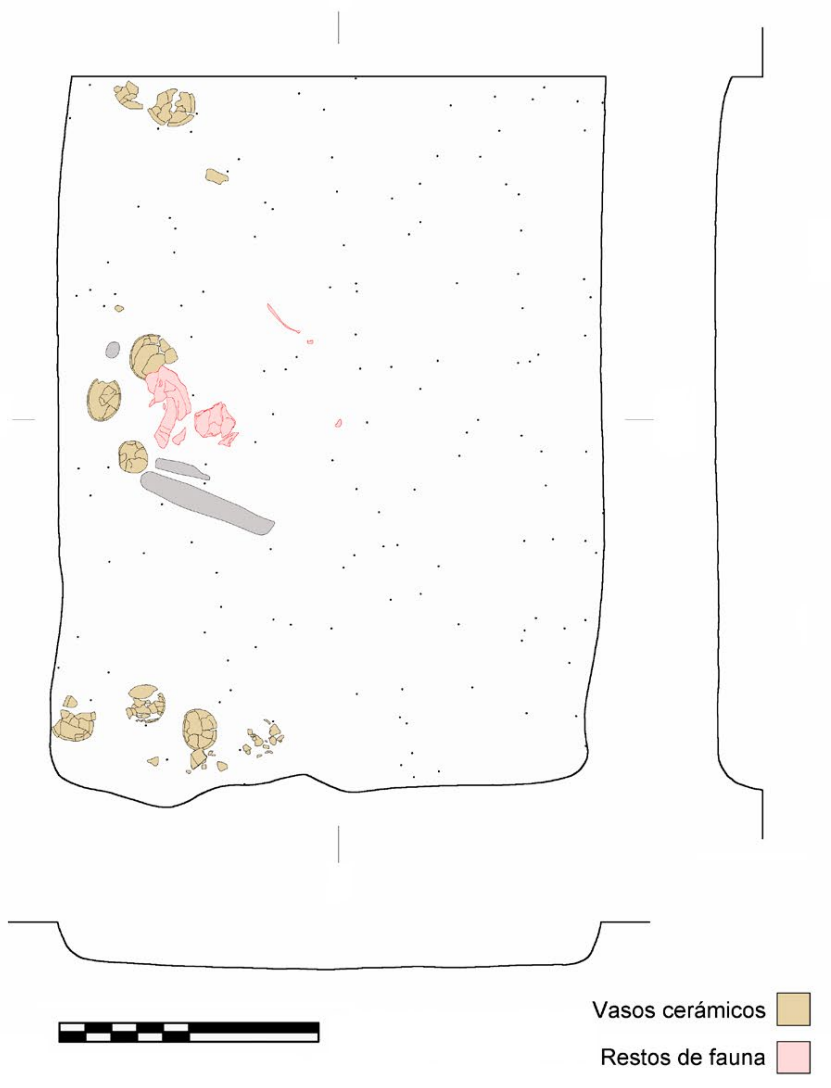

2

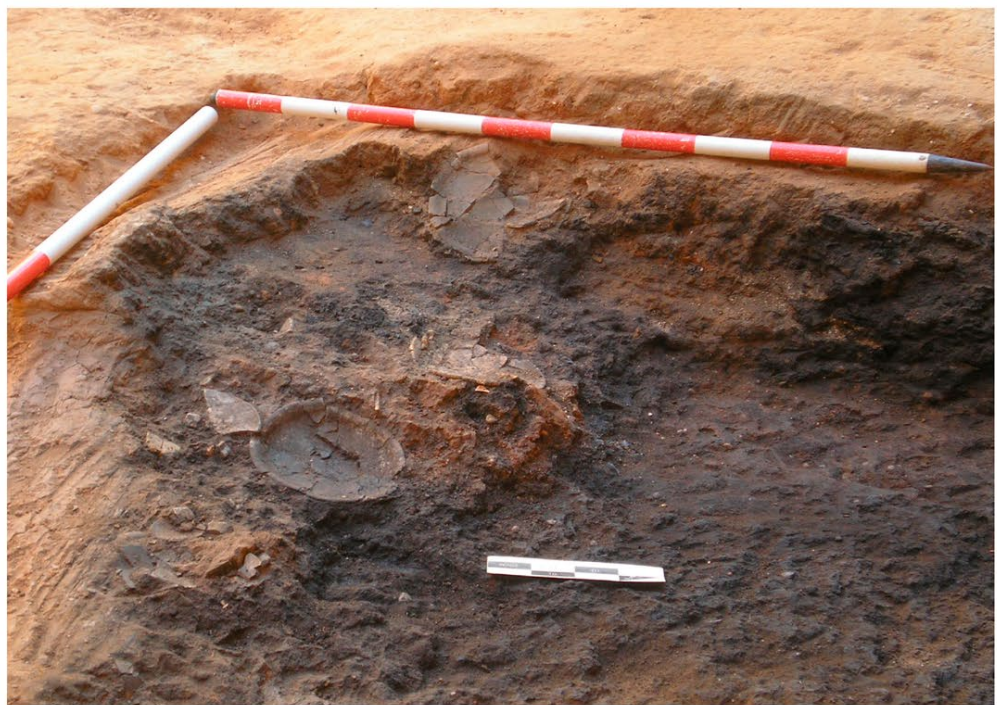

Figura 13: Planta y sección del posible enterramiento arcaico de la c/ Hércules (Sáez y Belizón, 2014: 186, fig. 4)

\section{LA CONFIGURACIÓN DEL ASENTAMIEN- TO URBANO INSULAR DE GADIR EN ÉPOCA ARCAICA}

A pesar de los evidentes avances, los datos son aún demasiado parciales y limitados y resulta difícil establecer un orden lógico, funcional y secuencial de los espacios arqueológicos habitados o productivos (Ruiz Mata et al., 2014: 92). No obstante, nuestro ánimo es intentar articular la información disponible a fin de concretar la naturaleza y extensión del núcleo urbano propiamente dicho, así como sus límites (espaciales y funcionales), los posibles espacios extraurbanos y su funcionalidad y los puertos de la ciudad. Sin olvidar la integración en el conjunto de las áreas funerarias y cultuales y su interpretación en relación con la ciudad. Un uso del suelo que, como en otras ciudades (por ej. Cartago: Fumadó, 2010), no fue estático sino dinámico y cambiante a través del tiempo. 

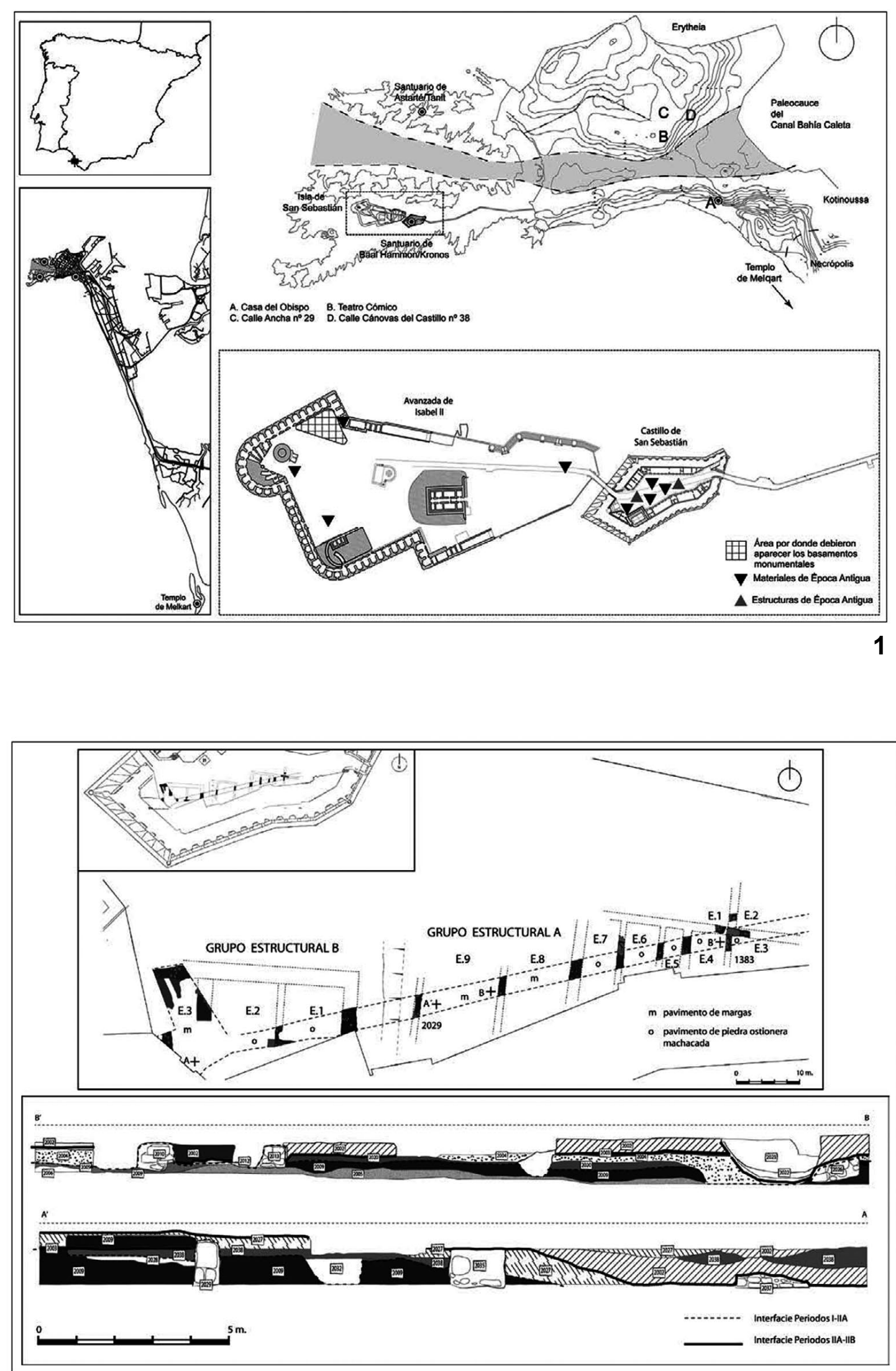

Figura 14: Intervenciones recientes (2009-2012) en el entorno del Castillo de San Sebastián, ubicación tradicional para el Templo de Baal-Hammón. 1. Localización y topografía del Castillo de San Sebastián (Maya et al., 2014: 157, fig. 1). 2. Planta y perfiles del Periodo I / Fenicio (Maya et al., 2014: 165, fig. 6) 


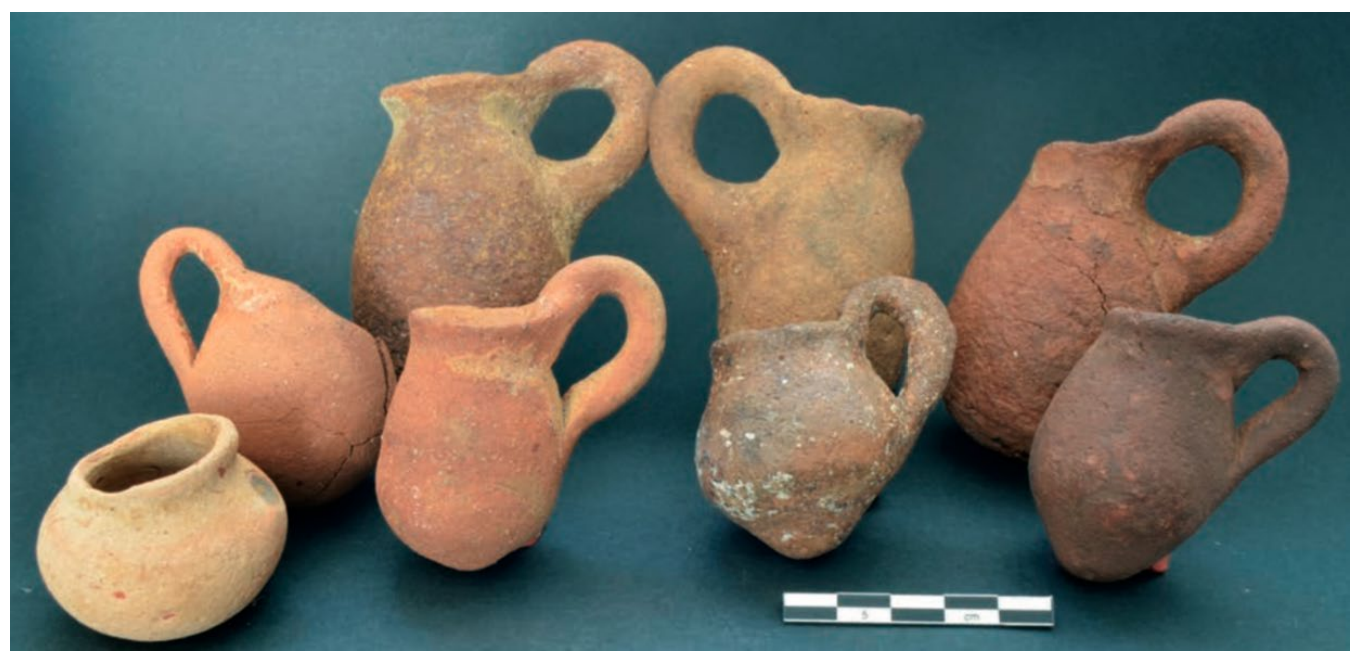

Figura 15: Materiales fenicios procedentes de prospecciones subacuáticas llevadas a cabo en los últimos años en el área de La Caleta (Sáez e Higueras-Milena, 2016: 134, fig. 7)

\subsection{EL CENTRO URBANO NUCLEAR}

Dada la aparente dispersión de restos constructivos, algunos autores han planteado la posibilidad de una estratigrafía horizontal para el asentamiento urbano (Ruiz Mata et al., 2014: 92). No obstante, creemos que existen argumentos historiográficos, topográficos, crono-estratigráficos y morfológicos suficientes para defender que el núcleo urbano original de Gadir se halla en la zona más alta de la isla de Erytheia, al menos en época arcaica (Fig. 16).

La topografía fenicia era bastante diferente de la actual (Fig. 17, 1). Las primeras viviendas del Teatro Cómico se elevan tan sólo unos $6 \mathrm{~m}$ sobre el nivel de playa antiguo, en un paisaje dunar prelitoral (Gener et al., 2014a: 17). Una suave elevación natural, con acceso desde el mar por el canal pero protegida hacia el interior (Fig. 17, 2). En cuanto a las dimensiones del primer recinto urbano existe cierta unanimidad sobre su reducido tamaño. Estrabón describe la ciudad anterior a la ampliación de Balbo como de pequeño tamaño (III, 5, 3) (Fig. 17, 3), aunque sólo podemos elucubrar sobre las dimensiones reales del asentamiento. Las 10 ha de algunos cálculos son a todas luces excesivas (Ramírez Delgado, 1982: 132), toda vez que la mayor parte de las colonias fenicias ocupaban entre $0,5-2,5$ ha (López Castro, 2018: 84), por lo que debió acercarse más a la hectárea propuesta por Domínguez Monedero (2012: 176); en cualquier caso, lejos de las 6-7 ha de Doña Blanca (Ruiz Mata, 2018: 270), las 8 del Cerro del Villar (Aubet, 2018: 325) y de las 10 de Cartago en época arcaica (Fumadó, 2010: 18). La extensión total de lo excavado en el Teatro Cómico se reduce a 470 $\mathrm{m}^{2}$, aunque los restos continúan bajo los cuatro perfiles del solar (Gener et al., 2014a: 45). En cualquier caso, la distancia lineal entre los diferentes puntos excavados no excede el centenar de metros, por lo que el núcleo urbano no debió extenderse hacia el $\mathrm{S}, \mathrm{E}$ y $\mathrm{N}$ mucho más allá del tell que corona el punto topográfico actual más elevado (Fig. 18). El hábitat se distribuiría por esta elevación y bajaría hasta las orillas del canal adaptándose a las características del terreno (Gener et al., 2014a: 17 y 36; Niveau de Villedary, e.p.). De hecho, se ha constatado que las viviendas de la primera ciudad fenicia se disponen en dos terrazas al menos, aunque el solar se aplana en la siguiente fase, tras la primera reconstrucción.

Con el tiempo el núcleo urbano se debió reducir (¿o extender hacia otra zona?), pues solo el barrio residencial de Teatro Cómico muestra una secuencia de ocupación de cerca de tres siglos (finales IX-tercer cuarto del VI a. C.) (Fig. 17, 4). El resto de sitios documentados sólo se ocupan en la primera fase, abandonándose a continuación, sin que conozcamos las razones.

Otra de las características de la ciudad fenicia es su elevada densidad. La totalidad del espacio excavado en el Teatro Cómico se ocupa en el Periodo Fenicio A y permanece a lo largo de las sucesivas reconstrucciones, lo que ofrece una idea del alto grado de ocupación del suelo en este sector, en el que apenas debieron quedar espacios libres sin urbanizar (Gener et al., 2014a: 37).

En cuanto a la morfología y características de la ciudad, el sector excavado constituiría una zona residencial, de un cierto nivel social y económico, dadas las dimensiones de las viviendas, algunos de sus equipamientos y los indicios de ciertas actividades llevadas a cabo en ellas (López Castro, 2017: 201). Se constata la existencia de un urbanismo planificado, con una arquitectura netamente oriental en las formas y técnicas y en los elementos subsidiarios como los hornos. Otros aspectos como el continuo remozado de las calles, son pruebas irrefutables de una actividad comunitaria propia de una ciudad (Gener et al., 2014a: 36). La existencia de escritura (Zamora et al., 2010) y las evidencias de actividades administrativas que se desprende del hallazgo de algunas bullae de arcilla (Gener et al., 2012) confirman también el carácter urbano del asentamiento. Las estancias, por su tamaño, disposición y por el tipo de actividades que se desarrollaron en ellas (cocina, actividades artesanales 

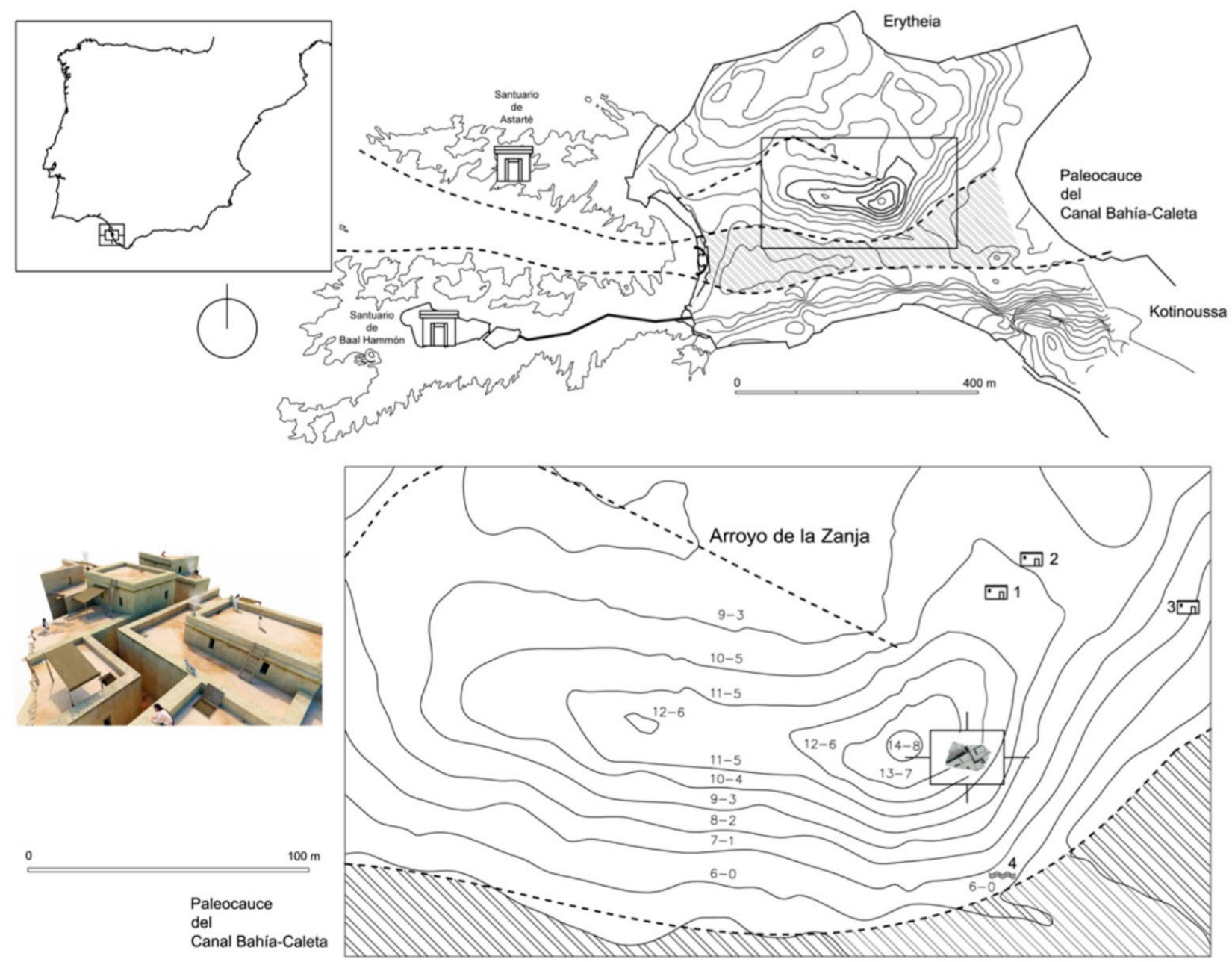

Figura 16: Extensión probable del núcleo urbano primitivo de Erytheia con la localización de los puntos principales con restos arcaicos: Teatro Cómico/TC (encuadrado), Calle Ancha/CA (1), Central Telefónica/CT (2), Cánovas del Castillo/CdC (3), Teatro Andalucía/TA (4) (Gener et al., 2014a: 15, fig. 1)

de autoconsumo, etc.), denotan su pertenencia a edificios privados, de carácter doméstico, aunque no todos los autores están de acuerdo, al menos para las fases más recientes (Padilla, 2014: 30-31).

No existen indicios de las supuestas murallas de la ciudad, en contraste con la documentación de potentes defensas en las ciudades situadas en la orilla continental de la bahía (Castillo de Doña Blanca y Cerro del Castillo). En este sentido, Ruiz Mata sugiere la existencia en las islas de un hábitat «disperso» en una ciudad «abierta» y carente de murallas (Ruiz Mata et al., 2014: 85). Por toponimia y tradición se piensa que el núcleo urbano insular debió estar también amurallado (Plinio, N.H. 4, 36, 120; Avieno, O.M., 267-269; Avieno, Descp. Orbis Terrae, 610-615), aunque quizás en este caso el significado del término $G D R$ esté más relacionado con la «insularidad» del asentamiento (Ruiz Cabrero et al., 2007: 393) que con la interpretación más habitual de «lugar «cercado o amurallado» (Ruiz Cabrero et al., 2007: 392-394), aunque siempre con sentido de «tejido urbano» (Ruiz Cabrero et al., 2007: 403). En cualquier caso nos movemos en el terreno de la especulación, toda vez que no ha aparecido indicio alguno de las pretendidas defensas de la ciudad fenicia (Niveau de Villedary, 2019a: 22, 36, n. 14, Apéndices II y III).

En suma, defendemos que la primitiva ciudad de Gadir se situó al sur de la isla de Erytheia sobre una suave elevación natural, confirmando lo que en otros trabajos hemos llamado el «Modelo Topográfico Clásico de Gadir», a raíz del trabajo de José Luis Escacena (1985) que sintetiza las opiniones de muchos de los autores anteriores a él (Niveau de Villedary, 2019a: 14-21; e.p.). En el punto topográfico más alto actual se emplazaría la posible acrópolis o área pública. $\mathrm{La}$ áreas residenciales se extenderían por sus flancos (como demuestra el importante sector de viviendas excavado) hasta llegar al paleocauce del «canal BahíaCaleta» por el $\mathrm{S}$ y el E, donde se localizan los límites periurbanos de funcionalidad económica. La ciudad posiblemente se extendiera por el $\mathrm{O}$ o $\mathrm{NO}$, aunque no tenemos certeza de ello. Hacia el $\mathrm{N}$ limitaría por un espacio no urbanizado pero sí ocupado, donde tendrían lugar actividades de tipo ritual en relación con la posible necrópolis de la ciudad. 

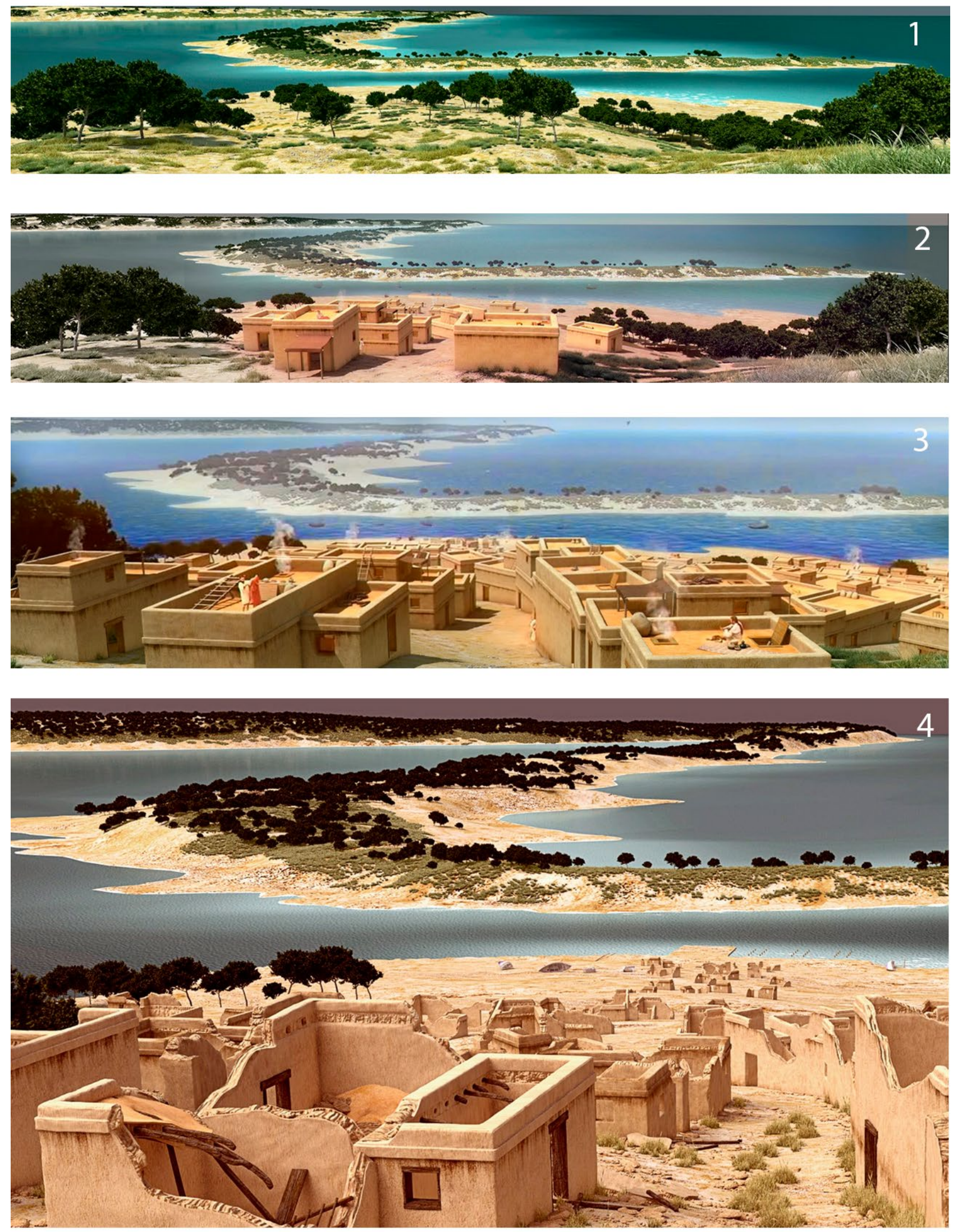

Figura 17: Reconstrucción virtual del paisaje antiguo (1) (Gener et al., 2014a: 17, fig. 2) y evolución del asentamiento fenicio de Teatro Cómico /Gadir. (2, 3, 4). CArtresD-J.A. Cordón. OCE.ps División de Ocio, Cultura y Entretenimiento /Vitelsa 


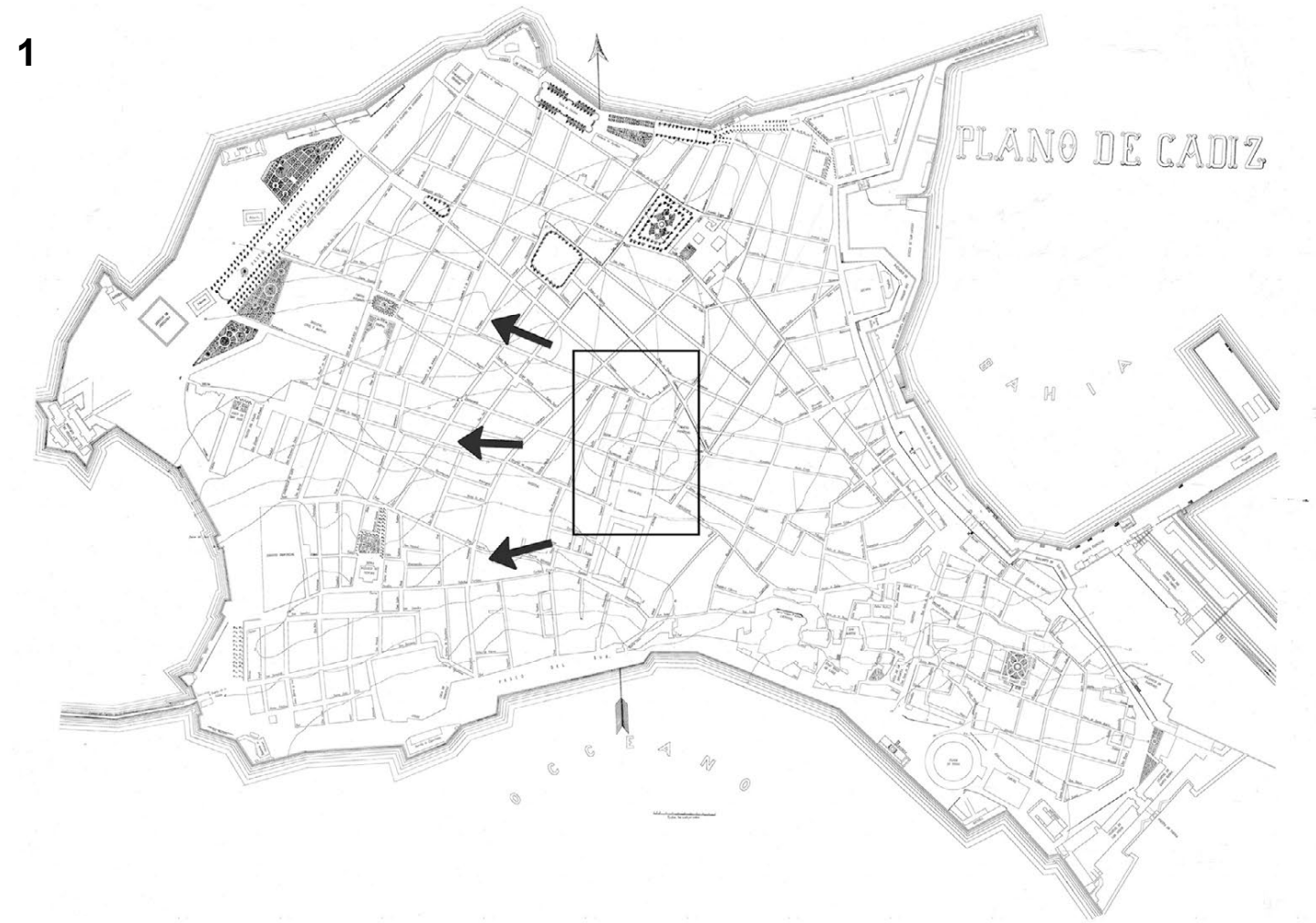

2

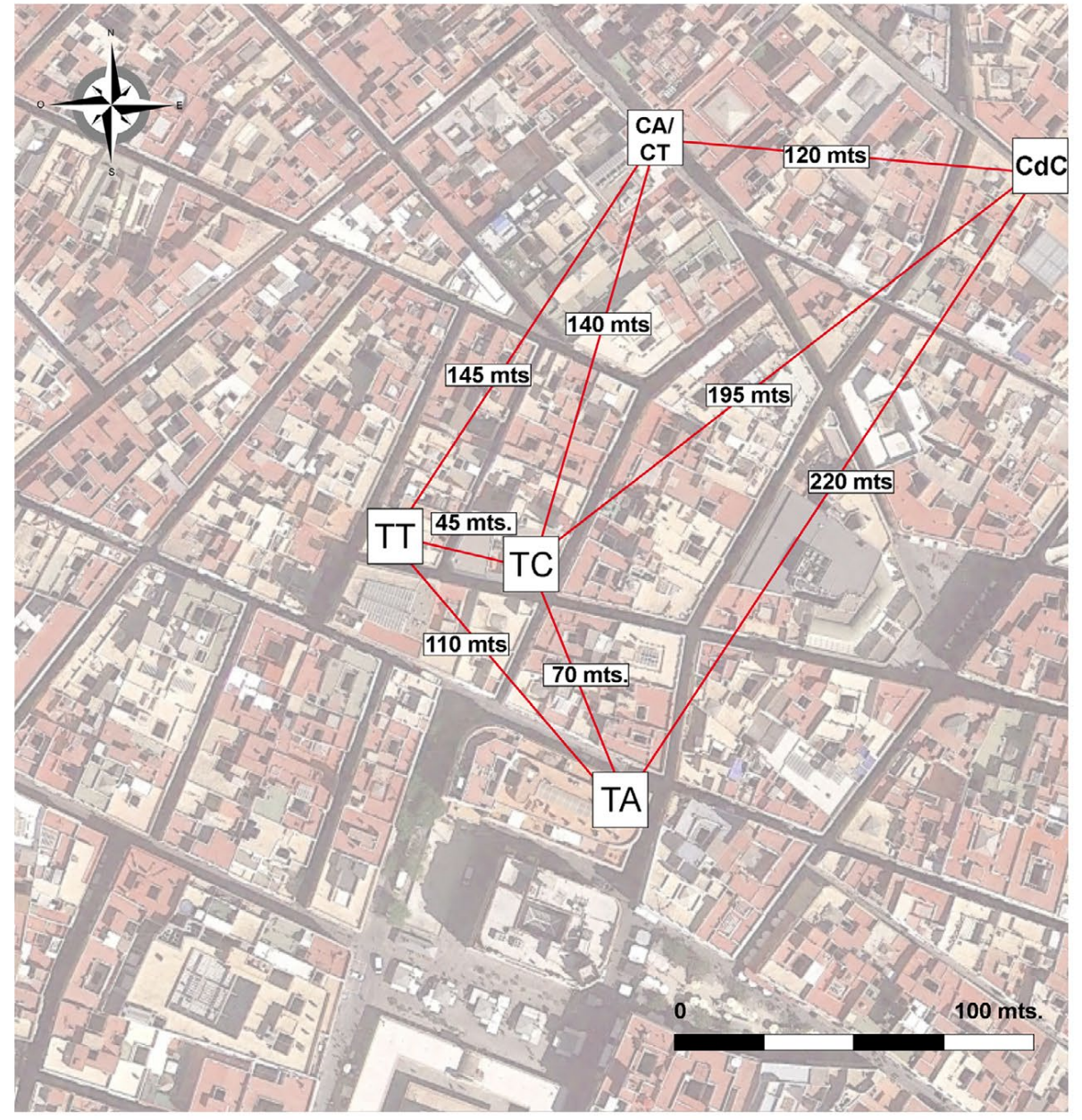

Figura 18: 1. Probable área de expansión del núcleo urbano principal. 2. Distancia entre los diferentes sitios excavados o que han proporcionado materiales fenicios arcaicos y (CAutora, modificado a partir de Ruiz Mata, 2016: 314, fig. 4 


\subsection{LOS LÍMITES DE LA CIUDAD. DELIMITACIÓN Y FUN- CIONALIDAD DEL ÁREA PERIURBANA DEL NÚCLEO DE ERYTHEIA}

A pesar de la dificultad para situar los límites físicos concretos de la ciudad en el estado actual de la investigación, pensamos que es posible aproximarnos a ellos, al menos a través de criterios de tipo funcionales.

4.2.1. El límite meridional. Las áreas portuarias, pesqueras y comerciales situadas en el «canal Bahía-Caleta»

El límite sur del asentamiento coincide con la orilla septentrional del canal. En esta zona, en el solar del antiguo Teatro Andalucía (TA), se reconoció un nivel fenicio de playa a una cota de 0,38 m s.n.m. (Lavado et al., 2000: 871) a tan sólo $77 \mathrm{~m}$ del núcleo residencial excavado. En dicho sector se evidencia actividad antrópica desde momentos tempranos aunque no queda bien definida (¿fogatas?, ¿vertederos?). Lo más probable es que se trate de restos originados por el movimiento habitual de la zona, habida cuenta de la cercanía a la ciudad, de la existencia de evidencias de actividades de autoconsumo de los propios trabajadores del fondeadero o del trasiego de mercancías que hubo de llevar aparejada la actividad mercantil y portuaria (Lavado et al., 2000: 872). No obstante, en el momento actual aún es difícil de precisar hasta qué punto este «sector portuario»o lugar de atraque estuviera integrado en la estructura urbana de la ciudad.

El límite oriental viene dado por los restos de habitación eventuales hallados en 2002 en la c/ Cánovas del Castillo, a unos $200 \mathrm{~m}$ lineales del centro urbano situado en el entorno de la Torre Tavira (Teatro Cómico y c/ Marqués del Real Tesoro) y a 215-220 m del punto costero anteriormente citado (TA). Los pavimentos y estructuras hallados formarían parte del sector periurbano meridional de la ciudad, un lugar de trabajo a cielo abierto relacionado con la pesca y el procesamiento primario de las capturas, que debían descargarse en los fondeaderos más cercanos. Esta zona quedaría fuera de los límites físicos estrictos de la ciudad, aunque es probable que formara parte de los «arrabales» periurbanos donde tendrían lugar diversas actividades económicas orientadas al aprovechamiento marino y al tráfico comercial, cuyos límites no serían fijos en el tiempo (Niveau de Villedary, e.p.).

4.2.2. El límite septentrional. Posibles áreas rituales, votivas y funerarias en el entorno inmediato de la ciudad

El área urbana de Teatro Cómico/Torre Tavira no se extiende hacia el N, aunque el área es ocupada por otro tipo de actividades.

La existencia de una necrópolis en Erytheia fue ya apuntada hace más de treinta años por Juan Ramón
Ramírez Delgado (1982: 104) que aludía a la posibilidad de que el cementerio arcaico se ubicara en los límites inmediatos del hábitat. Esta idea se apoyó en la aparición a principios del s. XX de la figurilla de Ptah (conocida como «sacerdote de Cádiz») en una estructura interpretada como tumba monumental, a unos 150 $\mathrm{m}$ al N (CT) del área residencial principal (TC).

La discusión sobre la funcionalidad de los restos se aviva con los hallazgos realizados a comienzos del milenio (CA) a escasos $20 \mathrm{~m}$ del anterior (CT). La estructura descubierta es interpretada en un primer momento como una tumba de pozo, pero tras su análisis material y contextual se ha considerado que tuviese una función votiva, siempre valorando su probable relación con la necrópolis (Ruiz Mata et al., 2014). El relleno del pozo muestra la sucesión de distintos rituales y sacrificios y la posible realización de banquetes rituales o funerarios (Ruiz Mata et al., 2014: 108). Sus editores fechan el conjunto en un momento similar a los hallazgos de Cánovas del Castillo, alrededor de la primera mitad del s. VIII a. C. o, más probablemente, hacia mediados de la centuria, siempre según la cronología convencional (Ruiz Mata et al., 2014: 113), lo que para los partidarios de las cronologías altas lleva el conjunto hasta finales del s. IX-comienzos del VIII a. C. (Zamora, 2010: 466). Por su parte, los caracteres del epígrafe hallado en el interior de la estructura parecen decantar la datación, en términos de probabilidad, hacia finales del s. VIII-principios del s. VII a. C., (Zamora, 2010: 475 y 480), sin que los datos paleográficos sean, según el propio autor, ni definitivos ni concluyentes (Zamora, 2010: 472).

\subsection{Puertos, FONDEAderos y ZONAS DE ATRAQUE}

La localización del puerto fenicio es otra de las cuestiones que ha interesado a la investigación a lo largo de la Historia. Los distintos autores de época moderna lo sitúan en un primer momento en la playa de La Caleta (O) (Ramírez Delgado y Mateos, 1985) antes de que se trasladara hacia la cara abierta a la bahía en época romana (E). Tras la identificación del canal interior, se propone la existencia de un doble puerto fenicio: el militar se sitúa en la playa de La Caleta y el comercial en una ensenada secundaria abierta al mar por el frente del Vendaval (hoy Campo del Sur). Ambos se comunicarían mediante un canal artificial. Otros autores creen que el puerto fenicio estaría resguardado en el interior del canal, al pie del altozano de la ciudad (Ramírez Delgado, 1982: 109). El trasiego de embarcaciones y las instalaciones portuarias provocarían el paulatino cegamiento de este curso de agua. Las investigaciones más recientes han sacado a la luz la existencia de este supuesto «puerto interior» en la actual Plaza de la Catedral. Según sus autores este espacio portuario estaría funcionando de una manera continuada desde finales del s. IX-comienzos del s. VIII a. C. hasta época romana (Arteaga y Roos, 2002: 26). Arteaga plantea que los fenicios establecieron el primer asentamiento alrededor 
de este puerto interior o kothon, de manera similar a los karum orientales, en su relación con las poblaciones vecinas locales (Arteaga y Roos, 2002: 32).

Las investigaciones subacuáticas más recientes en el área de la playa de La Caleta proponen la existencia de un puerto o fondeadero también es esta zona desde época arcaica, que perdura, al menos, hasta época romana, en función de la concentración de hallazgos en determinadas zonas de los arrecifes rocosos de la zona (Higueras-Milena y Sáez, 2018: 83). En particular, el área de «La Cepera» es la que ha proporcionado materiales arqueológicos más antiguos, recipientes anfóricos que evidencian un importante tráfico comercial desde época temprana, hasta el punto que los autores del estudio plantean que se trate del área portuaria original, que se conectaría directamente con los asentamientos (Teatro Cómico) y con las zonas de fondeaderos y descargas del interior del canal, al menos desde el s. VII a. C. (Higueras-Milena y Sáez, 2018: 93).

En suma, existirían dos puertos exteriores, uno abierto al Atlántico (en la playa de La Caleta) y otro hacia la bahía (en la ubicación del puerto actual) y, al menos, otros tres interiores: dos fondeaderos de poco calado en el frente abierto al océano Atlántico y, el más importante, el kothon o puerto interior situado en la zona de la moderna Catedral.

\subsection{LAS ÁREAS EXTRA-URBANAS DE LA ISLA MAYOR}

Los datos procedentes del extremo septentrional de la isla de Kotinoussa son, en líneas generales, posteriores cronológicamente. Posiblemente se trate de un área de expansión urbana o periurbana a partir de los ss. VII-VI a. C., con una funcionalidad industrial, portuaria o relacionada con los templos próximos (Niveau de Villedary, e.p.).

Los restos constructivos de los alrededores de la Catedral/Casa del Obispo (CdO) son considerados por sus excavadores extraurbanos, aunque con una funcionalidad doméstica (Gener et al., 2014b: 127-128). Para otros autores, sin embargo, formarían parte de la ciudad, caracterizada por un hábitat de carácter disperso (Ruiz Mata et al., 2014: 85). Otra posibilidad es que estemos ante una diferenciación vertical y fueran «barrios populares» que surgen en el extrarradio frente a las áreas residenciales acomodadas, representadas por la zona urbana de Teatro Cómico. La aparición de una tobera (Gener et al., 2014b: 127, fig. 2, e) podría relacionarse con la práctica de actividades metalúrgicas, por lo que podría constituir un área industrial periurbana y no doméstica como proponen los editores, al menos a modo de hipótesis de trabajo. Finalmente, también cabe la opción de que desde un primer momento esta zona desempeñe una funcionalidad cultual, como sucederá en etapas posteriores (Niveau de Villedary, e.p.).

En conclusión, en el estado actual del conocimiento los restos constructivos y los materiales exhumados pueden interpretarse tanto como barrios residenciales periféricos como instalaciones extraurbanas industriales relacionadas con distinto tipo de actividades: portuarias, industriales, comerciales e incluso rituales, etc. En cualquier caso, no parecen formar parte del núcleo habitacional principal, situado al $\mathrm{N}$ del canal. A partir de finales del s. VII la zona situada más al S comienza a utilizarse como cementerio (Torres, 2010: 56).

\subsection{LA NECRÓPOLIS ARCAICA DE ERYTHEIA}

Desde el punto de vista historiográfico existen dos posturas respecto a la ubicación de la primera necrópolis de la ciudad. Para un sector de la investigación el cementerio arcaico estaría situado en Erytheia, al N del asentamiento propiamente dicho (Ramírez Delgado, 1982: 102). Esta teoría se fundamenta en los hallazgos de la supuesta tumba monumental en cuyo interior apareció la figurilla del conocido como «sacerdote de Cádiz» (Ruiz Mata, 2018: 265). Otros investigadores defienden que la necrópolis fenicia se hallase en Kotinoussa en función de dos argumentos principales. En primer lugar, se subraya la continuidad espacio-temporal, ya que la necrópolis posterior ocupa esa zona, al menos desde finales del s. VII a. C. (Perdigones et al., 1990: 9-11; Blanco, 2008: 311; Abad y Corzo, 2017; Belizón et al. 2014; Niveau de Villedary et al., e.p.). El segundo de los argumentos es el topográfico, ya que el patrón de asentamiento habitual fenicio implica la separación física y simbólica entre las áreas de habitación y las funerarias, lo que generalmente tiene lugar mediante un curso de agua (Aubet, 2009: 275), que en el caso de Gadir se ha identificado tradicionalmente con el antiguo canal que cruzaba el casco histórico de la ciudad (Muñoz, 2008). El descubrimiento en 2010 de una posible tumba de época arcaica en la c/ Hércules (CH) (Sáez y Belizón, 2014) a $500 \mathrm{~m}$ al N del núcleo urbano principal contribuye a dar peso a la hipótesis de la existencia de un cementerio arcaico en Erytheia (Niveau de Villedary, 2019b: 1370). Se trata de una tumba de incineración en fosa primaria, similar en cuanto al rito empleado a los enterramientos tardoarcaicos de Gadir, pero alejada del modelo habitual de las estructuras funerarias fenicias de esta época en otras zonas, tanto de las necrópolis «populares» planas -como la de la propia metrópolis oriental de Tiro-Al-Bass (Aubet, 2010; Aubet et al., 2015) o la de Ayamonte (García Teyssandier et al., 2018)-, como de las segmentarias de corte «aristocrático» (López Castro, 2006), pues en ambos casos el rito funerario es la incineración secundaria y la posterior deposición de las cenizas en urnas. Tampoco los materiales hallados en el interior de la estructura gaditana responden al servicio funerario normalizado de los enterramientos fenicios: ni mediterráneos, ni gaditanos. El conjunto, realizado tanto a torno como a mano, está formado por una serie de platos y copas relacionados con la bebida $\mathrm{y}$ algunos elementos suntuarios (quemaperfumes, una 
placa de marfil, etc.), que remiten a prototipos orientales pero también recuerdan la tradición indígena.

Los datos son aun muy parciales para plantear, siquiera como hipótesis, la existencia de necrópolis fenicias de distinta naturaleza - «aristocráticas» y «planas»-repartidas por el territorio insular (Niveau de Villedary, 2015: 234-235; e.p.). En cualquier caso los habitantes del «barrio residencial» de Teatro Cómico, que seguramente gozaron de un cierto estatus social y económico, tendrían derecho a ser enterrados (no sabemos en cementerios de qué tipo, ni con qué bienes), en necrópolis segregadas de las que por ahora desconocemos todo: tanto su existencia, como su ubicación y su morfología, la tipología tumbal, el ritual asociado y el ajuar y demás materiales.

\subsection{TEMPLOS, SANTUARIOS, ZONAS DE CULTO Y VOTIVAS. EL DEBATE ACERCA DE LA SACRALIZACIÓN DEL PAISAJE INSULAR}

Las fuentes clásicas citan la existencia, aunque posteriores en el tiempo, de hasta tres templos en territorio insular. Esta circunstancia, unida a la falta de espacio, a la escasez de evidencias materiales y al reducido tamaño del asentamiento, ha llevado a algunos autores a proponer que el núcleo insular desempeñase un papel simbólico o sagrado (Ruiz Mata, 1999: 309). De acuerdo a esta explicación, la mayor parte de la población se aglutinaría en los centros urbanos continentales, donde también residiría el poder político y administrativo (Ruiz Mata et al., 2014: 83; Ruiz Mata, 2016: 315; 2018; Padilla, 2014: 31) y se concentrarían la mayor parte de las actividades económicas. Aunque no dudamos del carácter urbano del área excavada en Erytheia, la realidad es que en las islas, junto a los tres templos citados por las fuentes, se documentan otros espacios religiosos y/o sacros, tanto de naturaleza pública como seguramente privados.

El templo de Melqart, emplazado en el extremo S de Kotinoussa queda, desde un punto de vista espacial, fuera de este análisis. Representaría, tanto simbólica como físicamente, la frontera meridional de Gadir y hay que relacionarlo con el asentamiento en tierra firme del Cerro del Castillo (Chiclana, Cádiz). Los otros dos santuarios se localizan en el extremo $\mathrm{N}$ del archipiélago, próximos a la ciudad insular. Aunque se han planteado distintos emplazamientos, la propuesta más aceptada es que el santuario dedicado a Astarté estuviera situado en el extremo septentrional de la playa de La Caleta (en Erytheia) (Ramírez Delgado y Mateos, 1985), mientras que el Kronion, antiguo santuario de Baal-Hammón, se asienta en el extremo NW de Kotinoussa. En ninguno de los dos casos se cuenta con evidencias concluyentes. La ubicación del santuario de Astarté se apoya en la aparición bajo las aguas de un conjunto de figuras de terracota y elementos vasculares relacionados con el culto (López Sánchez, 2017), muchos de ellos inéditos (Ramírez Delgado y Mateos, e.p.) y otros en manos de coleccionistas privados. Junto a la información anterior, las más recientes actuaciones subacuáticas (HiguerasMilena y Sáez, 2018) están permitiendo geoposicionar los puntos donde los hallazgos son más frecuentes, lo que sin duda permitirá avanzar en el conocimiento de las actividades llevadas a cabo en este lugar desde época temprana (Sáez e Higueras-Milena, 2016). Tampoco existe certeza de la ubicación del Kronion en el lugar propuesto con la única base del hallazgo del capitel protoeólico en los alrededores (Marín Ceballos y Jiménez Flores, 2011), por lo que algunos autores habían propuesto que se tratara de un lugar sacralizado, sin construcciones (Ruiz Mata, 1999: 301). No obstante, en los últimos años han tenido lugar una serie de actuaciones arqueológicas que han sacado a la luz restos constructivos y materiales fechados desde el s. VII a. C. en adelante, aún por valorar (Maya et al., 2014).

Otra zona con carácter sagrado es el entorno de la Catedral actual, en la isla mayor. Dicho espacio se sacraliza a partir de finales del s. VI a. C. cuando empiezan a realizarse ofrendas y pequeños banquetes alrededor de un enterramiento monumental apartado de la necrópolis habitual (Gener et al., 2014b). Los restos constructivos arcaicos documentados bajo esta estructura son interpretados, como hemos visto, como espacios domésticos por sus excavadores, pero no hay que descartar sin más el carácter religioso de los mismos, habida cuenta tanto de la continuidad sagrada del espacio, que perdura hasta hoy, como la propia posición topográfica destacada del conjunto (Niveau de Villedary, e.p).

Una nueva línea de investigación que estamos iniciando en la actualidad, pone el énfasis en analizar la influencia del factor de visibilidad en la configuración del paisaje arcaico de la ciudad fenicia de Gadir utilizando como referencia los tres núcleos urbanos fenicios hasta hoy día hallados en la bahía gaditana (el insular, el Cerro del Castillo en Chiclana de la Frontera y el Castillo de Doña Blanca) y su relación con los tres santuarios que citan las fuentes clásicas. Aplicando el método de «Análisis de cuenca visual (teórica o potencial)» se está investigando en las relaciones de visibilidad existente entre cada una de las zonas de hábitat con los santuarios, el mar y el territorio circundante, así como entre ellas mismas (López Sánchez et al., e.p.). A partir de estos análisis se establecen una serie de interpretaciones teóricas sobre la asociación visual que dichos enclaves pudieron compartir y, con ello, un intento preliminar de comprender mejor la distribución espacial del conjunto gaditano en la Protohistoria y del papel de referentes para la navegación de los tres templos principales (López Sánchez et al., 2019).

\section{RECAPITULACIÓN Y CONCLUSIONES. LA EVOLUCIÓN CRONOLÓGICA Y ESPACIAL DE LA CIUDAD FENICIA}

La ocupación más antigua del solar gaditano se retrotrae a un momento indeterminado del Neolítico Final/ 
Calcolítico (Lazarich, 2003), con algunas evidencias de ocupación en el Bronce Pleno (Córdoba y Ruiz Mata, 2005: 1276) y posiblemente en el Bronce Final (Gener et al., 2014b: 125-127), no sabemos si en contacto ya con las poblaciones orientales. Aunque existen evidencias de una ocupación anterior (Periodo I - Bronce Final/Fenicio) (Gener et al., 2014a: 18), los niveles más antiguos documentados con seguridad en Gadir son los correspondientes al Periodo II - Fenicio A del sector urbano excavado en Erytheia/Teatro Cómico (Gener et al., 2014a: 16; Torres et al., 2014: 77-78; 2018).

Por lo tanto y desde un punto de vista secuencial, en Gadir no se ha identificado aún un nivel de ocupación que permita incluir la fundación de la ciudad en el «Horizonte Colonial temprano» definido en los últimos años gracias a los hallazgos de Huelva/Plaza de las Monjas, la Rebanadilla (Málaga) y el Carambolo (Sevilla) en la Península Ibérica (López Castro, 2018: 80) y Útica (Túnez) en el Mediterráneo central (López Castro et al., 2016: 83-84). En cualquier caso, es una cuestión que queda abierta a la espera de que el desarrollo de las investigaciones logre documentar esta «Fase Arcaica Inicial».

Tras esta primera y por ahora solo intuida etapa, definimos una «Fase Arcaica Temprana» para Gadir representada fundamentalmente por el Periodo II Fenicio A de Erytheia/Teatro Cómico (Niveau de Villedary, e.p.), cuyo inicio se ha situado hacia el $820 / 800$ a. C. y su final hacia el 760/750 a. C. (Gener et al., 2014a; Torres et al., 2014: 78; 2018: 183). Se corresponde con el Estrato IV de Tiro y su transición al Estrato III, a la transición entre el «Horizonte Salamis» (850-750 a. C.) y el «Horizonte Kition» (750-700 a. C.) de Chipre; y al Periodo III-IV de la necrópolis de Al-Bass (Torres et al., 2014: 51). Aunque los primeros pavimentos podrían retrotraerse al Estrato $\mathrm{V}$ de Tiro (Torres et al., 2014: 79). Esta etapa es contemporánea a la Fase B1a de Morro de Mezquitilla (Ramon, 2006: 192 ss.; Ramón, 2010: 218) y aunque en un principio se asimiló a las Fases III-II de La Rebanadilla (Sánchez et al., 2012: 69) hoy parece que el ya considerado santuario estuvo en funcionamiento durante un periodo muy corto de tiempo y que las tres primeras fases pueden datarse hacia finales del s. IX a. C. (Sánchez et al., 2018: 320), tanto por los materiales hallados como por las dataciones radiocarbónicas calibradas (Sánchez et al., 2018: 321; fig. 16), en un horizonte idéntico al conocido en Huelva (Plaza de las Monjas/Méndez Núñez) y, por tanto, anterior a la fase II de Teatro Cómico.

Los sectores periurbanos del centro urbano principal de Erytheia (CdC y CA) se corresponderían, a juicio de sus excavadores, con los Estratos III-II de Tiro por la presencia de platos de borde estrecho y ánforas ya de fabricación occidental T-10.1.1.1. (Ruiz Mata et al., 2014: 97). Algunos tipos anteriores podrían remitir a Tiro IV, aunque Ruiz Mata prefiere datar este horizonte de ocupación unifásico hacia mediados del s. VIII a. C. o en la primera mitad de la centuria (Ruiz Mata et al., 2014: 113).
El inicio de la ocupación en Koutinussa (CdO) se fecha también ca. 820/800 a. C. (Gener et al., 2014b: 123). Se ha propuesto un inicio de la actividad (Periodo I, 1) contemporánea con la Fase 1 del Período II de Erytheia/TC (Gener et al., 2014a: 125-127).

En cuanto al espacio funerario, el enterramiento situado al $\mathrm{N}$ del asentamiento $(\mathrm{CH})$ se data genéricamente en el s. VIII a. C., hacia mediados del mismo o en su segunda mitad (Sáez y Belizón, 2014: 193 y 197), fecha confirmada mediante dataciones radiométricas.

Pocos datos tenemos sobre otros espacios. Se ha propuesto que el puerto interior estuviera ya en funcionamiento en la transición de los ss. IX-VIII a. C. (Arteaga y Roos, 2002: 26 y 31). Más tardíos son los testimonios en relación con los espacios religiosos que se datan hacia finales del s. VII - principios del s. VI a. C. (Maya et al., 2014: 177).

A tenor de lo expuesto, metodológicamente es posible distinguir dos tendencias claramente diferenciadas a la hora de fechar los contextos analizados. La primera representada por el equipo de investigación del Teatro Cómico (TC), Casa del Obispo (CdO) y Castillo de San Sebastián (CSS), se caracteriza por proponer cronologías «altas» no sólo por la inclinación a utilizar las fechas corregidas frente a las dataciones históricas convencionales, sino sobre todo por apurar las dataciones de los contextos cerámicos poniendo el peso en los elementos más antiguos. Frente a ellos, D. Ruiz Mata el excavador del Castillo de Doña Blanca y editor de los conjuntos de calle Ancha y Cánovas del Castillo, adopta la postura opuesta, que le lleva a fechar dichos contextos a la «baja» (Ruiz Mata et al., 2014: 95). A esta última se adhieren los editores de la tumba de calle Hércules, que fechan el conjunto dentro del horizonte At1 definido por Joan Ramon (2010: 231-232) (en este caso las dataciones radiocarbónicas obtenidas ofrecen intervalos demasiado amplios para que puedan ser tenidas en cuenta a efectos de datación: Belizón y Sáez, 2014: 197, tabla 1). Si tomamos todos estos datos como tal, el resultado es la (aparente) mayor antigüedad de los dos puntos excavados por el primero de los equipos, que serían anteriores secuencialmente al resto de sitios arcaicos documentados. Mientras que para los primeros este momento se corresponde con la transición entre los «Horizontes Salamis/Kition» y los Estratos Tiro IV-III (con algunos elementos más antiguos que llevan al V), el segundo propone la correlación con la transición entre los «Horizontes Kition/ Amathus», Estratos Tiro III-II (con perduraciones del Estrato IV). A efectos secuenciales, la consecuencia principal es la «creación» de un hiatus poblacional, ya sea real o ficticio, de unos 40/50 años aproximadamente entre las secuencias ocupacionales de Teatro Cómico (TC) y de otros puntos cercanos como Calle Ancha (CA) o Cánovas del Castillo (CdC), cuando a tenor de lo descrito por los editores del Cómico, buena parte de los materiales de la Fase II del yacimiento se documentan también en estos otros puntos insulares e incluso entre los materiales más antiguos del 
Castillo de Doña Blanca (en el extremo cronológico más moderno) y los más recientes de Huelva (PM/MN) y la Rebanadilla, en el extremo más antiguo (Torres et al., 2018: 176-177).

Por lo tanto, opinamos que este desfase cronológico no es tal (o no debe serlo) cuando se analizan con mayor profundidad las secuencias materiales presentadas, y que resulta factible sostener la contemporaneidad de la mayor parte de estos conjuntos arcaicos -sin negar por completo la defendida mayor antigüedad de los restos de Teatro Cómico (Torres et al., 2014; 2018)-, puesto que a efectos secuenciales las cronologías de los distintos sitios se van, como poco, solapando. En cualquier caso la presencia de elementos relativamente «modernos» invita a reconsiderar a la baja las cronologías ofrecidas por los excavadores del Cómico, que no obstante habrá que comprobar cuando se publiquen las secuencias materiales completas asociadas a cada uno de los niveles (y subniveles) arqueológicos. Acercando ambas posturas, se podría aceptar la fecha propuesta por sus excavadores para el inicio de la Fase II de Teatro Cómico -sin perjuicio de la existencia de una fase anterior por ahora indefinida cronológicamente representada por el Periodo I de Teatro Cómico- pero, sin embargo, pensamos que su final se acerca más a la fecha propuesta por el equipo en los primeros trabajos publicados: 720 a. C. ca. (Zamora et al., 2010: 206), dado que los materiales de los diferentes sitios documentados se solapan y no parece existir ningún tipo de hiatus secuencial, al menos en la ocupación global de la isla. Nos resulta difícil creer que se estén documentando actividades antrópicas en los alrededores (CA, CdC) y no en el Cómico en estos mismos momentos cronológicos -mediados del s. VIII a. C.-, a menos que la primera destrucción de la ciudad generara una especie de «diáspora» de sus habitantes a las zonas cercanas y una vez reconstruido el hábitat principal se volviera a él, abandonándose a su vez estas zonas limítrofes, aunque la falta de estructuras edilicias y las evidencias de las actividades llevadas a cabo en estas otras áreas (productivas de carácter pesquero por una parte y votivo-rituales por otra) nos invita a desechar, a priori, esta explicación.

En cualquier caso el mayor problema que vemos (y que es el que hemos querido reflejar en estas líneas) es que se están fechando en diferentes momentos conjuntos materiales muy similares dependiendo del equipo que lo haga: mientras que unos optan por cronologías altas y enfatizan los materiales más antiguos (aun a riesgo de crear un hiatus en la secuencia general), otros equipos prefieren usar cronologías bajas, con el mismo resultado. Por nuestra parte, y dado que los materiales se solapan y no parece existir, por tanto, ningún tipo de hiatus, al menos en la ocupación global de la isla, proponemos que el momento de máxima expansión del núcleo urbano tendría lugar hacia el segundo cuarto-mediados de la centuria. Estas fechas estarían en consonancia con la dataciones relativas y absolutas de otros yacimientos con niveles similares ${ }^{1}$ y con la primera facies productiva definida por Ramón (2010: 218-219 y 231-232) para el Extremo-Occidente (M1 y At1).

Desde esta perspectiva, adquiere mayor sentido la existencia de una ciudad arcaica, que surge en un momento indeterminado de finales del s. IX o principios del VIII a. C. y que hacia el segundo cuarto o mediados de esta centuria alcanza su máximo desarrollo espacial.

El enclave arcaico de Teatro Cómico se abandona definitivamente $c a .520$ a. C. (Periodo IV) (Gener et al., 2014a) y la zona no se vuelve a ocupar hasta finales del s. III a. C., en un momento definido (y mediatizado) por la presencia cartaginesa en la ciudad y que, por tanto, responde a unos condicionantes históricos específicos y muy diferentes. El abandono final del núcleo arcaico se produce tras una serie de colapsos y sucesivas reconstrucciones y da lugar a un prolongado hiatus poblacional (ahora sí) que se prolonga hasta finales del s. III - principios del s. II a. C., cuando la zona adquiere una funcionalidad industrial. Tampoco se han localizado restos constructivos en las inmediaciones, ni materiales descontextualizados que permitan inferir cualquier tipo de actividad en la zona durante esos siglos, de lo que cabe deducir que el hábitat arcaico situado en Erytheia no tiene continuidad, al menos en el mismo emplazamiento.

Los excavadores del Teatro Cómico ponen en relación la destrucción del área urbana documentada a finales del Periodo III, donde se hallan los dos cadáveres en un nivel de cenizas, con algunos restos aparecidos en el Teatro Andalucía, un individuo en posición forzada (aunque se fechó siglos más tarde) y restos de cenizas sobre la duna que interpretan como los restos del incendio que acabó con este sector de la ciudad, esparcidos por un fuerte viento del norte (Gener et al., 2014a: 39 y 41). Esta circunstancia coincide en el tiempo con la disolución de la sociedad de época colonial y la sustitución de las antiguas estructuras por otras, aunque el hecho es que desconocemos tanto las causas del abandono del enclave original como el lugar donde hubo de trasladarse la población (Niveau de Villedary, 2014).

Entre las posibles causas para este traslado ya Ramírez Delgado planteó que el progresivo cegamiento del canal fuera una de las causas por las que se erigió una nueva ciudad, la Neápolis de Balbo (Ramírez Delgado, 1982: 133) y la transferencia de la población al lugar donde luego se asentaría la ciudad medieval, el actual barrio de El Pópulo y sus posteriores arrabales (barrios de Santiago y Santa María). La opinión generalizada es que el poblamiento se desplaza de la isla menor a la mayor aunque este acontecimiento se suele

1. Agradecemos a F. Prados la información sobre las dataciones de la muralla del Cabezo Pequeño del Estaño, en la desembocadura del río Segura, que han ofrecido una cronología entre el 790-760 a. C. (García y Prados, e.p.). 
hacer coincidir con la reforma urbanística promovida por Balbo que amplía la ciudad. Hoy sabemos que este traslado hubo de producirse bastante antes, al menos desde el tercer cuarto del s. VI a. C. según muestra el registro del Teatro Cómico.

Por su parte, el desplazamiento de la necrópolis a Kotinoussa debió ser anterior si nos atenemos a la documentación de las primeras tumbas de incineración a partir de finales del s. VII a. C. (ca. 600 a. C., Torres et al., 2014: 79).

En cuanto al lugar donde se traslada la ciudad, una opción es que se desplazara hacia el Norte, una vez que la necrópolis se reubica en la isla mayor, pero tampoco en esta zona se han hallado restos posteriores a época arcaica. La otra posibilidad es el traslado de la población al otro lado del canal, a la isla de Kotinoussa, donde también se han documentado vestigios de ocupación desde el s. VIII a. C., posiblemente extraurbana, en el actual barrio de Santa María (Lavado et al., 2000; Álvarez Rojas, 1992; Gener et al., 2014b), aunque desde finales del s. VII a. C. está constatado el uso de la zona como cementerio (Torres, 2010). En este sentido, la secuencia de ocupación ininterrumpida del yacimiento de la Casa del Obispo, con una importante actividad centrada en los ss. V-III a. C. invita a considerar, como hemos planteado en anteriores trabajos (Niveau de Villedary, 2014; 2015: 230) y a pesar de la naturaleza ritual de los restos documentados, que la ciudad «nueva» pudiera haberse refundado en su entorno, en los alrededores de la Catedral moderna y bajo la ciudad medieval, en el actual Barrio del Pópulo (Niveau de Villedary, 2014; 2015).

\section{REFERENCIAS}

Abad Casal, L. y Corzo Sánchez, R. (2017). Gadir/Gades/ Cádiz. Muchas novedades pendientes de una interpretación global. En M. M. Ros Sala (Ed.). Conviviendo con la Arqueología: Las capitales de las grandes potencias Mediterráneas en la Antigüedad. Una mirada alternativa (pp. 87-103). Murcia: Universidad Popular de Mazarrón. Recuperado de: https://www.um.es/arqueologia/wp-content/ uploads/2016/01/04-Gadir-Gades-C\%C3\%A1diz-Muchasnovedades-pendientes-de-una-interpretaci $\% \mathrm{C} 3 \% \mathrm{~B} 3 \mathrm{n}$-global. pdf

Álvarez Rojas, A. (1992). Sobre la localización del Cádiz fenicio. Boletín del Museo de Cádiz, V, 17-30.

Arteaga, O., Hoffmann, G., Schubart, H. y Schulz, H. D. (1987). Investigaciones geológicas y arqueológicas sobre los cambios de la línea costera en el litoral de la Andalucía Mediterránea. Informe preliminar. Anuario Arqueológico de Andalucía, 1985, III, 117-122. Recuperado de: https:// www.juntadeandalucia.es/export/drupaljda/1985 ACTIVIDADES_SISTEMATICAS web.pdf

Arteaga Matute, O. y Roos, A. M. (1995). El proyecto geoarqueológico de las marismas del Guadalquivir. Perspectivas arqueológicas de la campaña de 1992. Anuario Arqueológico de Andalucía, 1992, II, 329-339. Recuperado de: https://www.juntadeandalucia.es/export/drupaljda/1992_ SISTEMATICAS_web.pdf

Arteaga Matute, O. y Roos, A. M. (2002). El puerto fenicio-púnico de Gadir. Una nueva visión desde la geoarqueología urbana de Cádiz. Spal, 11, 21-39. DOI: http:// dx.doi.org/10.12795/spal.2002.i11.02

Arteaga Matute, O., Schulz, H. D. y Roos, A. M. (1995). El problema del «Lacus Ligustinus». Investigaciones geoarqueológicas en torno a las marismas del Bajo Guadalquivir. En Tartessos. 25 años después (1968-1993). Actas del Congreso Conmemorativo del V Symposium Internacional de Prehistoria Peninsular (Jerez, 1993) (pp. 99-135). Jerez de la Frontera: Ayuntamiento de Jerez de la Frontera.

Arteaga Matute, O., Schulz, H. D., y Roos, A. M. (2008). Geoarqueología Dialéctica en la Bahía de Cádiz. Revista Atlántica-Mediterránea de Prehistoria y Arqueología Social, 10, 21-116. Recuperado de: https://revistas.uca.es/index.php/ rampas/article/view/1370

Aubet Semmler, M. E. (2009). Tiro y las colonias fenicias de Occidente. Tercera edición actualizada ampliada. Barcelona: Bellaterra.

Aubet Semmler, M. E. (2010). The Phoenician Cemetery of Tyre. Near Eastern Archaeology, 73-2/3, 144-155. Recuperado de: https://www.upf.edu/documents/163262092/164235373/ AubetNea.pdf/ce38f559-49f5-a978-db2a-3184e67be8b8

Aubet Semmler, M. E. (2018). La colonia fenicia del Cerro del Villar. En M. Botto (Ed.). De Huelva a Malaka. Los fenicios en Andalucía a la luz de los descubrimientos más recientes (pp. 325-349). Roma: CNR Edizione.

Aubet Semmler, M. E., Núñez, F. J. y Trellisó, L. (Eds.). (2015). The Phoenician Cemetery of Tyre-Al Bass II. Archaeological Seasons 2002-2005. Beirut: Ministère de la Culture, Direction générale des antiquités.

Belizón Aragón, R., Botto, M. y Legupín Tubío, I. (2014). Conjunto funerario fenicio en el extremo sureste de la necrópolis de Gadir. En M. Botto (Eds.). Los Fenicios en la Bahía de Cádiz: Nuevas investigaciones (pp. 202-224). Roma: Fabrizio Serra ed.

Blanco Jiménez, F. J. (2008). Intervención arqueológica preventiva en un solar ubicado entre las calles Mirador 12, 14 y 16 y Santo Domingo 25 y 27 (Barrio de Santa María, Cádiz). Anuario Arqueológico de Andalucía, 2008. Cádiz, 308-316. Recuperado de: https://www.juntadeandalucia.es/ export/drupaljda/2008_C\%C3\%A1diz_0.pdf

Bondi, S. F., Botto, M., Garbati, G. y Oggiano, I. (2009). Fenici e cartaginesi. Una civiltà mediterranea. Roma: Libreria dello Stato, Istituto Poligrafico e Zecca dello Stato.

Botto, M. (2014). Los fenicios en la Bahía de Cádiz: estrategias de poblamiento y de aprovechamiento del territorio, relaciones con el mundo indígena, comercio (siglo IX- finales del siglo VII/inicios del VI a. C.). En M. Botto (Ed.). Los Fenicios en la Bahía de Cádiz: Nuevas investigaciones (pp. 265-281). Pisa-Roma: Fabrizio Serra Editore.

Botto, M. (Ed.). (2014). Los Fenicios en la Bahía de Cádiz: Nuevas investigaciones. Pisa-Roma: Fabrizio Serra Editore. 
Bueno Serrano, P. (2014). Un asentamiento del Bronce Final - Hierro I en el Cerro del Castillo, Chiclana, Cádiz. Nuevos datos para la interpretación de Gadeira.). En M. Botto (Ed.). Los Fenicios en la Bahía de Cádiz: Nuevas investigaciones (pp. 225-251). Pisa-Roma: Fabrizio Serra Editore.

Cobos, L., Muñoz, A. y Perdigones, L. (1995-96). Intervención arqueológica en el solar del antiguo teatro Andalucía de Cádiz: La factoría de salazones y la representación gráfica del Faro de Gades. Boletín del Museo de Cádiz, VII, 115-121.

Córdoba Alonso, I. y Ruiz Mata, D. (2005). El asentamiento fenicio arcaico de la calle Cánovas del Castillo (Cádiz). Un análisis preliminar. En S. Celestino y J. Jiménez (Eds.). El Periodo Orientalizante (pp. 1269-1322). Mérida: CSIC.

Delgado Hervás, A. (2008a). Fenicios en Iberia. En F. Gracia Alonso (Coord.). De Iberia a Hispania (pp. 347-474). Madrid: Ariel Prehistoria.

Delgado Hervás, A. (2008b). Cerro del Villar, de enclave comercial a periferia urbana: dinámicas coloniales en la bahía de Málaga entre los siglos VIII y VI a. C. En D. García I Rubert, I. Moreno Martínez y F. Gracia Alonso (Eds.). Contactes. Indígenes i fenicis a la Mediterrània occidental entre els segles VIII $i$ VI ane. (pp. 69-88): Alcanar: Ajuntament d'Alcanar.

Delgado Hervás, A. (2016). Producción artesanal y trabajo femenino en las comunidades fenicias occidentales: una mirada crítica a la teoría de las esferas separadas. En A. Delgado Hervás y M. Picazo Gurina (Eds.). Los trabajos de las mujeres en el mundo antiguo. Cuidado y mantenimiento de la vida (pp. 67-75). Tarragona: Institut Català d'Arqueologia Clàssica.

Domínguez Monedero, A. (2012). Gadir. En C. Fornis (Ed.). Mito y arqueología en el nacimiento de ciudades legendarias de la Antigüedad (pp. 153-197). Sevilla: Secretariado de Publicaciones, Universidad de Sevilla.

Escacena Carrasco, J. L. (1985). Gadir. Aula Orientalis, 3, 39-58. Recuperado de: http://www.aulaorientalis.org/ AuOr\%20escaneado/AuOr\%203-1985/Volumen\%203\%20 $-\% 20 N_{-} 1,2 / 3 . p d f$

Escacena Carrasco, J. L. (2018). Huelva-Aljaraque y el patrón poblacional fenicio de la costa tartésica. En P. Campos (Ed.). Arqueología y territorio en la provincia de Huelva: veinte años de las Jornadas de Aljaraque (1998-2017) (pp. 137-177). Huelva: Diputación de Huelva.

Fernández Camacho, P. (2015). A Space without Ethnology: Study of the Ideological Treatment of the West in Greek and Roman Literature through the Sources about the Island of Gades. L'Antiquité Classique, 84, 63-73.

Fernández Camacho, P. (2016). La ciudad bipolar. La construcción de la imagen de Cádiz en la historiografía del siglo XVI a través de las fuentes clásicas. Ágora. Estudos Clássicos em Debate, 18, 193-215.

Frutos Reyes, G. de y Muñoz Vicente, Á. (2004). La implantación colonial fenicia arcaica en el archipiélago de las Gadeira: una propuesta para el debate. Huelva en su Historia $2^{a}$ Época, 11, 83-106. Recuperado de: http://rabida. uhu.es/dspace/bitstream/handle/10272/3143/b15140659 pdf? sequence $=1$

Fumadó Ortega, I. (2010). Cartago: Usos del suelo en la ciudad fenicia y púnica. Archivo Español de Arqueología, 83, 9-26. DOI: https://doi.org/10.3989/aespa.083.010.001

García Menárguez, A. y Prados Martínez, F. (e.p.). Del primer impacto fenicio a la consolidación del fenómeno urbano en la costa de Alicante: El Cabezo Pequeño del Estaño y el santuario del Castillo de Guardamar. En J. L. López Castro (Ed.). Entre Útica y Gadir. Navegación y colonización fenicia en Occidente a comienzos del I milenio AC.

García Teyssandier, E., Marzoli, D., Cabaco Encinas, B., Heussner, B. y Gamer-Wallert, I. (2018). Phoenician necropolis in Ayamonte (Huelva, Spain). A preliminary report. En M. Botto (Ed.). De Huelva a Malaka. Los fenicios en Andalucía a la luz de los descubrimientos más recientes (pp. 217-272). Roma: CNR Edizione.

Gavala y Laborde, J. (1992 [1959]). Geología de la costa y bahía de Cádiz. El poema Ora Marítima de Avieno. Cádiz: Servicio de Publicaciones de la Diputación de Cádiz.

Gener, J. M., Navarro, M. A., Pajuelo, J. M., Torres, M. y Domínguez-Bella, S. (2012). Las crétulas del siglo VIII a. C. de las excavaciones del solar del Cine Cómico (Cádiz). Madrider Mitteilungen, 53, 134-186.

Gener, J. M., Navarro, M. A., Pajuelo, J. M., Torres, M. y López, E. (2014a). Arquitectura y urbanismo de la Gadir fenicia: el yacimiento del 'Teatro Cómico' de Cádiz. En M. Botto (Ed.). Los Fenicios en la Bahía de Cádiz: Nuevas investigaciones (pp. 14-50). Pisa-Roma: Fabrizio Serra Editore.

Gener, J. M., Jurado, G., Pajuelo, J. M. y Torres, M. (2014b). El proceso de sacralización del espacio en Gadir: el yacimiento de la Casa del Obispo (Cádiz). Parte I. En M. Botto (Ed.). Los Fenicios en la Bahía de Cádiz: Nuevas investigaciones (pp. 123-155). Pisa-Roma: Fabrizio Serra Editore.

Higueras-Milena Castellanos, A. y Sáez Romero, A. M. (2018). The Phoenicians and the Ocean: trade and worship at La Caleta, Cadiz, Spain. The International Journal of Nautical Archaeology, 47(1), 81-102. DOI: https://doi. org/10.1111/1095-9270.12275

Lavado, M. L., Molina, M., Cobos, L., Blanco, F. y Sibón, F. (2000). El asentamiento antiguo de Cádiz a través de las últimas excavaciones arqueológicas. En Actas del IV Congreso Internacional de Estudios Fenicios y Púnicos (Cádiz, 1995), II (pp. 869-879). Cádiz: Servicio de Publicaciones, Universidad de Cádiz.

Lazarich González, M. (2003). Informe preliminar del Proyecto de estudio de los materiales arqueológicos Calcolíticos y de comienzos de la Edad del Bronce, hallados en excavaciones de urgencia realizadas en el casco urbano de Cádiz. Anuario Arqueológico de Andalucia, 2000. II. Actividades Sistemáticas y Puntuales, 85-96. Recuperado de: https://www.juntadeandalucia.es/export/drupaljda/Anuarioarqueologico/Anuario-2000/Sistematicas.pdf

Llave, E., Hernández-Molina, F. J., Alonso Villalobos, C., Gallardo Abarzuza, M., Vázquez, J. T. y López-Aguayo, F. (1999). Caracterización y evolución del paleocauce del río Guadalete en la bahía de Cádiz durante el cuaternario 
terminal. Geogaceta, 26, 43-46. Recuperado de: http://rabida. uhu.es/dspace/handle/10272/10078

López Castro, J. L. (2006). Colonials, merchants and alabaster vases: the western Phoenician aristocracy. Antiquity, 80, 74-88. DOI: https://doi.org/10.1017/S0003598X00093273

López Castro, J. L. (2017). The social structure and political institutions of Western Phoenicians in the Extreme West of the Mediterranean. Rivista di Studi Fenici, 45(1), 199-218.

López Castro, J. L. (2018). MQM. Phoenician Emporia in the South of the Iberian Peninsula (9th to 7th Centuries BC). En E. Gailledrat, M. Dietler y R. Plana-Mallart (Eds.). The Emporion in the Ancient Western Mediterranean. Trade and Colonial Encounters from the Archaic to the Hellenistic Period (pp. 79-90). Montpellier: Presses Universitaires de la Méditerranée.

López Castro, J. L., Ferjaoui, A., Mederos, A., Martínez, V. y Ben Jerbania, I. (2016). La colonización fenicia inicial en el Mediterráneo Central: nuevas excavaciones arqueológicas en Utica (Túnez). Trabajos de Prehistoria, 73(1), 68-89. DOI: https://doi.org/10.3989/tp.2016.12164

López Sánchez, N. (2017). Análisis historiográfico sobre el santuario de Astarté en Gadir. Revisión crítica, puesta al dia $y$ nuevas perspectivas de investigación. (Trabajo de fin de máster). Universidad de Cádiz. Cádiz.

López Sánchez, N., Niveau de Villedary, A. M., y Gómez González, J. I. (2019). The Shrines of Gadir (Cadiz, Spain) as References for Navigations. GIS Visibility Analysis. Open Archaeology, 5, 284-308. DOI: https://doi.org/10.1515/ opar-2019-0019

López Sánchez, N., Niveau de Villedary, A. M., Sicre González, P. y Gómez González, J. I. (e.p.). La relación entre el hábitat urbano y los santuarios de Gadir (Cádiz, España). Una propuesta de análisis de visibilidad mediante SIGs. En S. Celestino Pérez y E. Rodríguez (Eds.). Actas del IX Congreso Internacional de Estudios Fenicios y Púnicos. Un viaje entre el Oriente y el Occidente del Mediterráneo (Mérida, 2018). Mérida: Instituto de Arqueología de Mérida. CSIC - Junta de Extremadura.

Marín Ceballos M. C., y Jiménez Flores, A. M. (2011). El Kronion de Gadir: una propuesta de análisis. En M. C. Marín Ceballos (Ed.). Cultos y ritos de la Gadir fenicia (pp. 221-245). Cádiz: Servicio de Publicaciones, Universidad de Cádiz.

Maya, R., Jurado, G., Gener, J. M., Torres, M., López, E. y Zamora, J. Á. (2014). Nuevos datos sobre la posible ubicación del Kronion de Gadir: las evidencias de época fenicia. En M. Botto (Ed.). Los Fenicios en la Bahía de Cádiz: Nuevas investigaciones (pp. 156-180). Pisa-Roma: Fabrizio Serra Editore.

Muñoz Vicente, Á. (1995-1996). Secuencia histórica del asentamiento fenicio-púnico de Cádiz: un análisis cronoespacial tras quince años de investigación arqueológica. Boletín del Museo de Cádiz, VII, 77-105.
Muñoz Vicente, Á. (1998). Notas sobre la necrópolis fenicia de Cádiz. En Homenaje al Profesor Carlos Posac Mon (pp. 131-141). Ceuta: Instituto de Estudios Ceutíes.

Muñoz Vicente, Á. (2008). Topografía y ritual en la necrópolis fenicio-púnica de Cádiz. En F. J. Guzmán Armario y V. Castañeda Fernández (Eds.). Vida y muerte en la Historia de Cádiz (pp. 57-84). Cádiz: Cemabasa.

Niveau de Villedary y Mariñas, A. M. (2008). Estado de la cuestión y nuevas perspectivas de la arqueología púnica en la Península Ibérica: el caso de la bahía de Cádiz. En J. P. Vita y J. Á. Zamora (Eds.). Nuevas Perspectivas II: La arqueología fenicia y púnica en la Península Ibérica (pp. 81-12). Barcelona: Ediciones Bellaterra. Recuperado de: http://www.raco.cat/index.php/CuadernosArqueologia/ article/view/241028

Niveau de Villedary y Mariñas, A. M. (2010). 'Deconstruyendo' paradigmas. Una (re)visión historiográfica crítica al modelo interpretativo tradicional del Cádiz feniciopúnico a la luz de los nuevos datos. En E. Ferrer (Ed.). Los Púnicos de Iberia: proyectos, revisiones, sintesis (pp. 619671). Málaga: Diputación Provincial de Málaga. Recuperado de: http://www.cedma.es/catalogo/mainake.php?ref=13022

Niveau de Villedary y Mariñas, A. M. (2015). La estructuración del espacio urbano y productivo de Gadir durante la Fase Urbana Clásica: cambios y perduraciones. Complutum, 26(1), 225-242. DOI: http://dx.doi.org/10.5209/rev CMPL.2015. v26.n1.49351

Niveau de Villedary y Mariñas, A. M. (2018). Gadir revisited. A proposal for reconstruction of the Archaic Phoenician foundation. Vicino Oriente, XXII, 91-109. Recuperado de: http://www.journal-vo.it/Publicazioni/VO\%20XXII/VO XXII PDF Autori/VO XXII 091-109 Niveau.pdf

Niveau de Villedary y Mariñas, A. M. (2019a). La fundación arcaica de Gadir. La construcción historiográfica de una ciudad ¿real o inventada?. Archivo Español de Arqueología, 92, 7-41. DOI: https://doi.org/10.3989/aespa.092.019.001

Niveau de Villedary y Mariñas, A. M. (2019b). 'La ciudad de los muertos'. Ensayo de reconstrucción topográfica del paisaje funerario de Gadir. En A. Ferjaoui y T. Redissi (Eds.). La vie, la mort et la religion dans l'univers phénicien et punique. Actes du VIIème Congrès International des Études Phéniciennes et Puniques (Hammamet - Túnez, 9-14 noviembre 2009) (pp. 1365-1391). Túnez: Institut National du Patrimoine.

Niveau de Villedary y Mariñas, A. M. (e.p.). La Gadir arcaica: cronología, topografía y morfología urbana. En J. L. López Castro (Ed.). Entre Útica y Gadir. Navegación y colonización fenicia en Occidente a comienzos del I milenio $A C$. Granada: Editorial Comares.

Niveau de Villedary, A. M., López Sánchez, N., Macías López, M. M., Sicre González, P., Blanco Jiménez, F. J., Legupín Tubío, I.,... y Martelo Fernández, M. (e.p.). Avance al estudio de la necrópolis fenicia de la «Casacuartel de la Guardia Civil»/San Severiano n. 10 (Cádiz, España). Primeros datos espaciales y arqueométricos. En S. Celestino Pérez y E. Rodríguez González (Eds.). Un viaje entre el Oriente y el Occidente del Mediterráneo. Actas del 
IX Congreso Internacional de Estudios Fenicios y Púnicos. (Mérida, 2018). Mérida: Instituto de Arqueología de Mérida. CSIC - Junta de Extremadura.

Padilla Monge, A. (2014). Los inicios de la presencia fenicia en Cádiz. Gerión, 32, 15-56. DOI: http://dx.doi.org/10.5209/ rev GERI.2014.v32.46664

Pajuelo Sáez, J. M. (2017). El segundo puente romano de Cádiz. Manuscrito inédito. Recuperado de: https://www. academia.edu/38711080/EL SEGUNDO PUENTE ROMANO DE C\%C3\%81DIZ

Perdigones, L., Muñoz, A. y Pisano, G. (1990). La necrópolis fenicio-púnica de Cádiz. Siglos VI al IV a. C. Roma: Università degli Studi di Roma.

Ponce Cordones, F. (2000). Sobre la ubicación del Cádiz fenicio. En Actas del IV Congreso Internacional de Estudios Fenicios y Púnicos (Cádiz, 1995), II (pp. 905-914). Cádiz: Servicio de Publicaciones, Universidad de Cádiz.

Prados Martínez, F. (2004). ¿Almacenes o centros redistribuidores de carácter sacro? Una reflexión en torno a un modelo arquitectónico tipificado en la protohistoria mediterránea. En A. González Blanco, G. Matilla Séiquer y A. Egea Vivancos (Eds.). El Mundo Púnico. Religión, Antropología y cultura material (pp. 173-180). Murcia: Universidad de Murcia. Recuperado de: https://www.um.es/cepoat/estudiosorientales/ wp-content/uploads/2018/01/Estudios_Orientales_n5_13.pdf

Prados Martínez, F. (2007). Los Fenicios. Del monte Líbano a las columnas de Hércules. Madrid: Marcial Pons.

Ramírez Delgado, J. R. (1982). Los primitivos núcleos de asentamiento en la ciudad de Cádiz. Cádiz: Exmo. Ayuntamiento de Cádiz. Recuperado de: https://cadizilustrada.files.wordpress.com/2011/04/asentamientofenicio.pdf

Ramírez Delgado, J. R. y Mateos Alonso, V. (1985). La arqueología subacuática en la bahía de Cádiz. En VI Congreso Internacional de Arqueología Submarina (Cartagena, 1982) (pp. 75-81). Madrid: Ministerio de Educación Cultura y Deporte, Dirección General de Bellas Artes y de Conservación y Restauración de Bienes Culturales.

Ramírez Delgado, J. R. y Mateos Alonso, V. (e.p.). Las terracotas femeninas fenicio-púnicas de la «Punta del Nao» (Cádiz) y el templo de la Venus Marina. Boletín del Museo de Cádiz, Monográfico In Memoriam Dña. Concepción Blanco Mínguez.

Ramon Torres, J. (2006). La proyección comercial mediterránea y atlántica de los centros fenicios malagueños en época arcaica. Mainake, XXVIII, 189-212. Recuperado de: http:// www.cedma.es/catalogo/mainake.php?ref=13018

Ramon Torres, J. (2010). La cerámica fenicia del Mediterráneo Extremo-Occidental y del Atlántico (s. VIII-1 ${ }^{\text {er }} 1 / 3$ del VI AC). Problemas y perspectivas actuales. En Motya and the Phoenician Ceramic Repertoire between the Levant abd the West (9th-6th century BC) (pp. 211-253), Roma: Università di Roma «La Sapienza».

Ruiz Mata, D. (1999). La fundación de Gadir y el Castillo de Doña Blanca: Contrastación textual y arqueológica. Complutum, 10, 279-317. Recuperado de: http://revistas. ucm.es/index.php/CMPL/article/view/CMPL9999110279A
Ruiz Mata, D. (2016). Las ciudades fenicias del Castillo de Doña Blanca y Cádiz durante el s. VIII a. C. Mi visión actual según los datos recientes. Rivista di Studi Fenici, XLIV, 305-318.

Ruiz Mata, D. (2018). Gadir, su estructura plural. Un modo de ver su fundación fenicia en el espacio y en el tiempo. Revista Onoba, 6, 249-288. Recuperado de: http://rabida. uhu.es/dspace/handle/10272/15614

Ruiz Mata, D., Pérez, C. J., y Gómez, V. (2014). Una nueva zona fenicia de época arcaica en Cádiz: el solar de la 'Calle Ancha, n. ${ }^{\circ}$ 29'. En M. Botto (Ed.). Los Fenicios en la Bahía de Cádiz: Nuevas investigaciones (pp. 83-122). Pisa-Roma: Fabrizio Serra Editore.

Sáez Romero, A. M. y Belizón Aragón, R. (2014). Excavaciones en la calle Hércules, 12 de Cádiz. Avance de resultados y primeras propuestas acerca de la posible necrópolis fenicia insular de Gadir. En M. Botto (Ed.). Los Fenicios en la Bahía de Cádiz: Nuevas investigaciones (pp. 181-201). Pisa-Roma: Fabrizio Serra Editore.

Sáez Romero, A. M. e Higueras-Milena Castellanos, A. (2016). Cerámicas fenicias arcaicas de procedencia subacuática del área de la Caleta (Cádiz): ensayo de contextualización e interpretación histórica. Cuadernos de Prehistoria y Arqueología de la Universidad Autónoma de Madrid, 42, 119142. DOI: http://dx.doi.org/10.15366/cupauam2016.42.004

Sáez Romero, A. M., Lara Medina, M. y Bernal Casasola, D. (2019). Indicios de la ocupación fenicio-púnica en la isla menor gaditana. En D. Bernal Casasola, J. M. Vargas Girón y M. Lara Medina (Eds.). 7 metros de la Historia de Cádiz... Arqueología en El Olivillo y en el Colegio Mayor Universitario (pp. 169-235). Cádiz: Editorial UCA, Universidad de Cádiz.

Sagona, C. (2004). The Phoenicians in Spain from a central Mediterranean Perspective: A Review Essay. Ancient Near Eastern Studies, 41, 240-266. DOI: http://dx.doi.org/10.2143/ ANES.41.0.562930

Sánchez Sánchez-Moreno, V., Galindo San José, L., Juzgado Navarro, M. y Dumas Peñuelas, M. (2012). El asentamiento fenicio de la Rebanadilla a finales del siglo IX a. C. En E. García Alfonso (Ed.). Diez años de Arqueología Fenicia en la Provincia de Málaga (pp. 67-85). Sevilla: Consejería de Cultura y Deporte, Junta de Andalucía.

Sánchez Sánchez-Moreno, V., Galindo San José, L., Juzgado Navarro, M. y Belmonte Marín, J. A. (2018). La Rebanadilla, santuario litoral fenicio en el sur de la península Ibérica. En M. Botto (Ed.). De Huelva a Malaka. Los fenicios en Andalucía a la luz de los descubrimientos más recientes (pp. 305-323). Roma: CNR Edizione.

Torres Ortiz, M. (2010). Sobre la cronología de la necrópolis fenica arcaica de Cádiz. En A. M. Niveau de Villedary y V. Gómez (Eds.). Las necrópolis de Cádiz. Apuntes de arqueología gaditana en Homenaje a J. F. Sibón (pp. 31-67). Cádiz: Diputación de Cádiz - Universidad de Cádiz.

Torres, M., López, E., Gener, J. M., Navarro, M. A. y Pajuelo, J. M. (2014). El material cerámico de los contextos fenicios del 'Teatro Cómico' de Cádiz: un análisis. En M. Botto (Ed.). Los Fenicios en la Bahía de Cádiz: Nuevas investigaciones (pp. 51-82). Pisa-Roma: Fabrizio Serra Editore. 
Torres, M., Gener, J. M., Navarro, M. Á., Pajuelo, J. M. y López, E. (2018). Los materiales cerámicos de la fase II (820-750 a. C.) de las excavaciones efectuadas en el Teatro Cómico (Gadir/Cádiz). En M. Guirguis (Ed.). From the Mediterranean to the Atlantic: people, goods and ideas between East and West. II. 8th International Congress of Phoenician and Punic Studies (Italy, Sardinia Carbonia, Sant'Antioco 21th-26th October 2013) (pp. 176-185). PisaRoma: Fabrizio Serra Editore.

Zamora López J. Á. (2010). Epigrafía y cronología: el nuevo grafito fenicio procedente del solar «de la Calle Ancha» de
Cádiz y su eventual datación paleográfica. En A. M. Niveau de Villedary y V. Gómez (Eds.). Las necrópolis de Cádiz. Apuntes de arqueología gaditana en Homenaje a J.F. Sibón (pp. 461-483). Cádiz: Servicio de Publicaciones de la Diputación de Cádiz - Servicio de Publicaciones de la Universidad de Cádiz.

Zamora, J. Á., Gener, J. M., Navarro, M. A., Pajuelo, J. M. y Torres, M. (2010). Epígrafes fenicios arcaicos en la excavación del Teatro Cómico de Cádiz (2006-2010). Rivista di Studi Fenici, XXXVIII(2), 203-36. 